\title{
Clinical and Epidemiological Characteristics of COVID-19 Mortality in Saudi Arabia: A Retrospective Multi-Center Study
}

Rawabi Alsayer ( $\nabla$ rm.alsayer@msd.med.sa )

Armed Forces Medical Services

Hassan Alsharif

King Fahd Armed Forces Hospital

Abeer AL Baadani

Prince Sultan Military Medical City

Kiran Kalam

Prince Sultan Military Medical City

\section{Research Article}

Keywords: Coronavirus, COVID-19, Epidemiology, Mortality, Characteristics, Saudi Arabia

Posted Date: February 26th, 2021

DOI: https://doi.org/10.21203/rs.3.rs-276027/v1

License: (c) (i) This work is licensed under a Creative Commons Attribution 4.0 International License.

Read Full License 


\section{Clinical and Epidemiological Characteristics of COVID-19 Mortality in Saudi Arabia: A Retrospective Multi-Center Study}

\section{Rawabi Alsayer, BHSc}

Epidemiologist - Research officer, Armed Forces Medical Services. Riyadh. Saudi Arabia.

Email: rm.alsayer@msd.med.sa - RALSAYER@PSMMC.MED.SA

ORCID ID: https://orcid.org/0000-0002-6153-2196

Hassan Alsharif, MD, FRCPc, ABIM

Director of Intensive Care Services, King Fahad Armed Forces Hospital, Jeddah, Saudi Arabia.

Email: alsharif hassan@yahoo.ca

Abeer Mohammed AL Baadani, MD

Internist and Infectious Disease consultant, Prince Sultan Military Medical City, Riyadh. Saudi Arabia.

Email: aalbadani@psmmc.med.sa

Kiran Kalam, MD

Infectious Disease senior Register, Prince Sultan Military Medical City, Riyadh. Saudi Arabia.

Email: kirankalam78@gmail.com 


\section{Abstract:}

Background: Coronavirus disease 2019 (COVID-19) has resulted in considerable morbidity and mortality worldwide since December 2019. This study highlights the significant burden of the COVID-19 outbreak, particularly in patients' health and the healthcare system. This study's clinical implication provides insight into the significant death indicators among COVID-19 patients in Saudi Arabia. Exploring these indicators will help physicians triage patients, identify critically ill patients, and prioritize ICU admissions by identifying high-risk medical and clinical indicators.

Methods: A multi-center retrospective study conducted among all COVID-19 mortality cases, admitted to 15 of Armed forces hospitals across Saudi Arabia regions during March July 2020. Demographic data, clinical presentation, laboratory investigations, and complications of COVID-19 mortality cases were collected and analyzed. According to the WHO, death due to COVID-19 was classified as a direct and indirect cause of death.

Results: A total of 224 COVID-19 mortality cases were included in the analysis. The mean age was $69.66 \pm 14.68$ years, and $142(63.4 \%)$ of the cases were male. $30 \%$ of overall COVID19 mortalities occurred in the first 24 hours of hospital admission, while $50 \%$ of the mortalities occurred on day 10 . There was a highly significant difference in the survival time (days) between cases admitted to the Intensive care unit (ICU) and general ward ( $p$-values $<.001$ ), as well as a significant difference in the survival time (days) between the direct and indirect cause of death from COVID-19 cases ( $p$-values 0.012). The most prevalent comorbidities were diabetes mellitus (DM) occurred in 165(73.7\%), and hypertension (HTN) in 156(69.6\%). Logistic regression for risk factors in all mortality cases revealed that direct mortality cases from COVID-19 are more likely to develop acute respiratory distress syndrome and acute kidney injury [OR 1.75 ( $\mathrm{Cl}$ 0.89-3.43); $\mathrm{p=.102}$ ], [OR 1.01 (Cl 0.54-1.90); $p=.960]$.

Conclusions: The prevalence of underlying diseases DM and HTN is high among COVID-19 mortality cases in Saudi Arabia. Multiple organ dysfunction can be observed, the most common organ damage, lungs, heart, followed by the kidney. The rising of serum ferritin, Procalcitonin, CRP, and D-dimer levels can be used as indicators of disease progression. 


\section{Keywords:}

Coronavirus, COVID-19, Epidemiology, Mortality, Characteristics, Saudi Arabia 


\section{Introduction}

The outbreak of disease caused by Severe Acute Respiratory Syndrome Corona Virus-2 (SARSCoV-2) was declared as a pandemic by the World Health Organization on the 11th of March 2020.1, and on the 1st of May, 2020, there have been more than 5 million confirmed cases of COVID-19 worldwide.(1)(2) The new strain of coronavirus was identified in December 2019 in Wuhan city, China, and has been named (SARS-CoV-2). The virus originates from the same coronavirus family as the Middle East Respiratory Syndrome (MERS-COV) and Severe Acute Respiratory Syndrome (SARS-COV). Yet, there is limited knowledge of its virologic course and pathogenesis.(1)(3)

During the initial phase of the COVID-19 outbreak, the disease's diagnosis was complicated by the diversity in symptoms and imaging findings (no symptoms as fever or radiologic abnormalities on the initial presentation) and the severity of disease at the time of presentation.(4)

Patient characteristics such as, old age, male sex, chronic comorbidity, hospital care, previous immunity, and virus mutations have consistently been associated with increased mortality.(5),(6) Evidence indicates that the COVID-19 mortality rate varies significantly across countries, from over $16 \%$ in France to less than $0.1 \%$ in Singapore. Such wide variation implies that there are factors that determine COVID-19 mortality such as, patient characteristics, hospital care, and government response.(7)'(6)

In Saudi Arabia, the Ministry of Health $(\mathrm{MOH})$ reported the first case of coronavirus Infection (COVID-19) on the 2nd of March 2020. As of the 6th of December 2020, a cumulative total of 358,713 COVID-19 cases and 5,965 deaths were reported in Saudi Arabia.(8) A national crosssectional study described the demographic and clinical characteristics of COVID-19 Patients 
in Saudi Arabia. It reported that nearly $20 \%$ of the patients had underlying comorbidities, as $8.8 \%$ hypertension and $7.6 \%$ diabetes. In contrast, $71.6 \%$ of patients were admitted to hospitals, and $4.7 \%$ required ICU treatment. However, the study's clinical outcomes could not be fully assessed.(9)

There is limited evidence on the factors that determine COVID-19 mortality such as, patient characteristics and hospital health care in the Middle East and KSA in particular. As COVID-19 pandemic has placed an unprecedented strain on health systems, with rapidly increasing healthcare demand in hospitals and, in particular, intensive care units (ICUs) worldwide. Projecting and determining the future demand for healthcare resources (beds, staff, equipment) has become a key priority for many countries as the pandemic escalates. The present study aims to fill this gap.

In this study, the data on epidemiological, clinical, laboratory investigations of 224 COVID-19 mortality cases were collected retrospectively and analyzed. Exploring the clinical and epidemiological factors associated with COVID-19 mortalities will add significantly to the body of knowledge of the outbreak's burden in KSA and Worldwide. This study highlights the significant burden of the COVID-19 outbreak, particularly in patients' health and the healthcare system. This study's clinical implication provides insight into the significant death indicators among COVID-19 patients. These indicators may help physicians triage patients, identify critically ill patients, and prioritize ICU admissions by identifying high-risk medical and clinical indicators. Subsequently, it will help control and prevent the outbreak, improve the public's health, and minimize this outbreak's burdens. 


\section{Method}

\section{Study design and setting}

A multi-center retrospective cross-sectional study was conducted to describe the clinical and epidemiological characteristics of COVID-19 Mortality cases admitted to Armed Forces Medical Services hospitals (MSD) across all regions of the Kingdom of Saudi Arabia (KSA). MSD has 26 hospitals around the KSA with a total bed capacity of 7,782 beds, of it 2,247 beds for 24 hours use. In addition to several beds are operated during crises and al-Hajj season. In this study, the data of mortality cases obtained from 15 of the MSD hospitals.

\section{Study Population}

A respiratory sample (nasopharyngeal swab, sputum, or tracheal aspirate) was collected for COVID-19 laboratory screening using a polymerase chain reaction (PCR) test per the protocol established by the World Health Organization (WHO).(10) Confirmation of a COVID-19 infection was then reported based on a positive PCR result, done at the National Health Laboratory or MSD Hospitals labs. All confirmed COVID-19 infections mortality cases admitted to MSD hospitals between (March -July 2020) and with a complete MOH (COVID-19 mortality Data Collection Sheet) data were included in this study. Exclusion criteria were COVID-19 mortality cases with unavailable or incomplete data.

\section{Data collection}

Data of mortality cases were obtained from the MSD Center for Infection Prevention and Control (CIPC) using the MOH data collection sheet (COVID-19 Mortality Data collection sheet). [Appendix:1] The Data collection sheet was initiated and developed by the Saudi MOH (updated in June 2020), including mortality cases epidemiological and clinical characteristics. 


\section{- Epidemiological and Clinical Characteristics}

Epidemiological and clinical characteristics of COVID-19 mortality cases include demographics, hospital, symptoms, comorbidities, co-infection, laboratory, level of care (admitted to ICU, was resuscitated, and Do-Not-Resuscitate (DNR)), investigations (chest X-ray), medications, and complications.

\section{- Biomarker Trends}

Biomarker trends include, Lymphocytes (\%), Serum Ferritin (pmol/L),D-dimer $(\mathrm{mcg} / \mathrm{mL})$, Serum Creatinine (SrCr) (mol/L), C-reactive protein(CRP) (mg/l) and Procalcitonin $(\mathrm{mcg} / \mathrm{l})$ were collected at (Day of presentation, Day (3-4) and 24-hr prior death) for mortality cases ( $n=115$ ) admitted to Prince Sultan Military Medical City (PSMMC). In this study, the laboratory data were collected and analyzed from onecenter due to the lack of data availability from MSD hospitals. PSMMC considered the biggest tertiary referral center from all other MSD hospital

\section{- $\quad$ Time to Death Analysis}

To observe and analyzed the time to death of COVID-19 hospitalized mortality cases. The date of hospital admission till the date of death (Days) for each hospitalized mortality case was calculated. Then, Kaplan-Meier survival estimates (Time to death) were applied to analyzed and presented the duration (Days) and group comparison (direct and indirect cause of death from COVID-19, ICU and general ward admission, and DNR and full code).

\section{- CFR and ICU bed occupancy rate}

The case fatality rate in epidemiology is defined as the proportion of die cases from a specified disease among all individuals diagnosed with the disease over a certain period of time. High rates of CFR are indicative of relatively poor outcomes. CFR is 
typically used to measure disease severity and is often used for prognosis (predicting disease course or outcome). It also can be used to evaluate the treatments and quality of patient care. CFR varies between populations and over time, depending on the interplay between the disease's causative agent, the host, the environment, and available treatments and patient care quality. (11)

As this study aimed to observe and evaluate the association between COVID-19 CFR and ICU bed occupancy rate (patient care) (April-July 2020). The CFR was calculated for the Six highest MSD hospitals in KSA in terms of COVID-19 mortality reporting. The Six hospitals' location included in the calculation was Riyadh, Khamis Mushait, Taif, AlKharj, Jeddah, and Tabuk. Then the ICU bed occupancy rate was calculated for each hospital.

Data independently entered into electronic sheets. All measures were taken to preserve the integrity and privacy of data. All subjects were assigned a study identification number. The electronic database was secured with passwords, and access was limited to selected investigators. Ethical approval was obtained from the Armed Forces Medical Services Scientific Research Center, Central Research Ethics Committee (Approval number 2020-012).

\section{Outcomes}

The primary outcome was to determine COVID-19 mortality factors such as patient clinical and epidemiological characteristics and hospital care. Patient characteristics such as age, sex, and major chronic comorbidity, have consistently been associated with increased mortality.

\section{Statistical analysis}

All data analyzed using descriptive and inferential statistics via IBM SPSS version 25.

Descriptive statistics, including means standard deviations, have been calculated for 
continuous variables (normally distributed) such as age. Non-normally distributed variables were represented as medians. Categorical variables such as gender, symptoms, and comorbidities have been presented as frequencies and percentages.

Inferential statistics including, Chi-Square test applied to compare variables across the cause of death from COVID-19, was made (direct, indirect). T-tests were applied to compare the means of normally distributed variables between the group. Wilcoxon Signed Ranks test was applied to compare laboratory biomarker trends across (day of presentation and 24-hr prior death). Logistic regression was applied for the significant variables. Kaplan-Meier was used to present and analyze (Time to death) of hospitalized mortality cases and compare groups (direct and indirect, ICU and general ward, and DNR and full code) in terms of time to death using the log-rank test. The results have been presented as odds ratio (OR) and 95\% Cl. A P value $<.05$ considered statistically significant.

\section{Variable Definitions}

Fever was defined as an oral temperature of $38^{\mathrm{C}}$ or higher.(12) Death due to COVID-19 was defined as a death resulting from a clinically compatible illness in confirmed COVID-19 case where is no clear alternative cause of death (e.g., trauma), no period of complete recovery from COVID-19 between illness and death, and unattributable to pre-existing conditions that could trigger a severe disease course (e.g., cancer). The variable cause of death from COVID19 was determined to direct, indirect according to the WHO. Cases classified as direct when COVID-19 immediate cause of death, and indirect when COVID-19 illness that initiated the train of events leading to death.(13) The clinical application of Do-Not-Resuscitate (DNR) followed in the study cases and in Saudi Arabia, which refers to, in the event of a cardiac 
and/or pulmonary deterioration or arrest, cardiopulmonary resuscitative measures will not be initiated, according to the Saudi Health Council policies and procedures.(14) 


\section{Results}

\section{Table 1}

Baseline Characteristics of Coronavirus Disease 2019 (COVID-19) Mortality Cases Admitted to Armed Forces Hospitals during (March - July 2020), ( $n=224)$

\begin{tabular}{|c|c|}
\hline Baseline characteristics & $224(100.0 \%)$ \\
\hline \multicolumn{2}{|l|}{ Gender } \\
\hline Male & $142(63.4)$ \\
\hline Female & $82(36.6)$ \\
\hline Age (Year) a & $69.66 \pm 14.68$ \\
\hline \multicolumn{2}{|l|}{ Nationality } \\
\hline Saudi & 208(92.9) \\
\hline Non-Saudi & $16(7.1)$ \\
\hline \multicolumn{2}{|l|}{ City } \\
\hline Riyadh & 115(51.3) \\
\hline Alkharj & $32(14.3)$ \\
\hline Taif & $18(8.0)$ \\
\hline Jeddah & $14(6.3)$ \\
\hline Tabouk & $11(4.9)$ \\
\hline Almadina & $7(3.1)$ \\
\hline Dhahran & $7(3.1)$ \\
\hline Khamis Mushait & $7(3.1)$ \\
\hline Wadi Aldawasir & $5(2.2)$ \\
\hline Hafr Albatin & $3(1.3)$ \\
\hline Najran & $2(0.9)$ \\
\hline Jazan & $2(0.9)$ \\
\hline Jubial & $1(0.4)$ \\
\hline \multicolumn{2}{|l|}{ Source of Hospital Admission } \\
\hline Emergency room & 198(88.4) \\
\hline Intra hospital transfer (from within) & $8(3.6)$ \\
\hline Transfer from another hospital & $7(3.1)$ \\
\hline Unknowing & $11(4.9)$ \\
\hline \multicolumn{2}{|l|}{ Occupation } \\
\hline Non-Health Care Worker & 222(99.1) \\
\hline Health Care Worker & $2(0.9)$ \\
\hline \multicolumn{2}{|l|}{ Smoker } \\
\hline Yes & $12(5.4)$ \\
\hline No & $207(92.4)$ \\
\hline Not Documented & $5(2.2)$ \\
\hline \multicolumn{2}{|l|}{ Blood type } \\
\hline $\mathrm{B}$ & 109(48.7) \\
\hline 0 & $68(30.4)$ \\
\hline$A$ & $35(15.6)$ \\
\hline$A B$ & $12(5.4)$ \\
\hline \multicolumn{2}{|l|}{ Rh Factors } \\
\hline Positive & $215(96.0)$ \\
\hline
\end{tabular}




\begin{tabular}{|l|c|}
\hline Negative & $9(4.0)$ \\
\hline A direct contact with another COVID-19 patient & \\
\hline Yes & $75(33.5)$ \\
No & $143(63.8)$ \\
Not Documented & $6(2.7)$ \\
\hline Do-Not-Resuscitate (DNR) & \\
\hline DNR & $109(48.7)$ \\
Full Code & $115(51.3)$ \\
\hline Resuscitated & \\
\hline Yes & $109(48.7)$ \\
\hline No & $115(51.3)$ \\
\hline Intensive Care Unit (ICU) & $142(63.4)$ \\
\hline Yes & $82(36.6)$ \\
\hline No & \\
\hline Intubated & $156(69.6)$ \\
\hline Yes & $68(30.4)$ \\
\hline No & $10(0-90)$ \\
\hline Length of Hospital Stay (Day) ${ }^{b}$ & \\
\hline Death was anticipated & $193(86.2)$ \\
\hline Yes & $31(13.8)$ \\
\hline No & $164(73.2)$ \\
\hline Cause of Death From COVID-19 & $60(26.8)$ \\
\hline Direct & \\
\hline Indirect & \\
\hline Mean & \\
\hline
\end{tabular}

${ }^{\mathrm{a}}$ Mean $\pm \mathrm{SD},{ }^{\mathrm{b}}$ Median (Minimum - Maximum)

\section{Baseline characteristics}

As of March till July 2020, 224 (1.0\%) of the 21078 patients with COVID-19 pneumonia died in MSD hospitals. Table 1 shows the demographic and epidemiological characteristics of 224 COVID-19 mortality cases admitted to MSD hospitals, were enrolled in the study. A 164(73.2\%) of the mortality cases had a direct death from COVID-19, while 60(26.8\%) had an indirect death from COVID-19. The majority of the mortality cases, 115(51.35\%) were admitted to Riyadh, 32(14.3\%) were admitted to Alkharj, followed by $18(8.0 \%)$ were admitted to Taif. 142 (63.4\%) were male, and the entire mortality cases had a mean age of $69.66 \pm 14.68$ years and $10(0-90)$ days of the length of hospital stay (LOS). 
In the level of care and admission to general ward or intensive care units (ICUs), 142 (63.4\%) of COVID-19 mortality cases were admitted to the ICU, while $82(36.6 \%)$ were admitted to the general ward. Most of the mortality cases were intubated $156(69.6 \%)$, and the death was anticipated among 193(86.2\%) of the cases. [Table 1 and Fig 1] 
Table 2

Clinical and Epidemiological Characteristic of Coronavirus Disease 2019 (COVID-19) Mortality Cases Admitted to Armed Forces Hospitals during (March - July 2020), Stratified by Cause of Death from COVID-19 (Direct - Indirect ), $(n=224)$

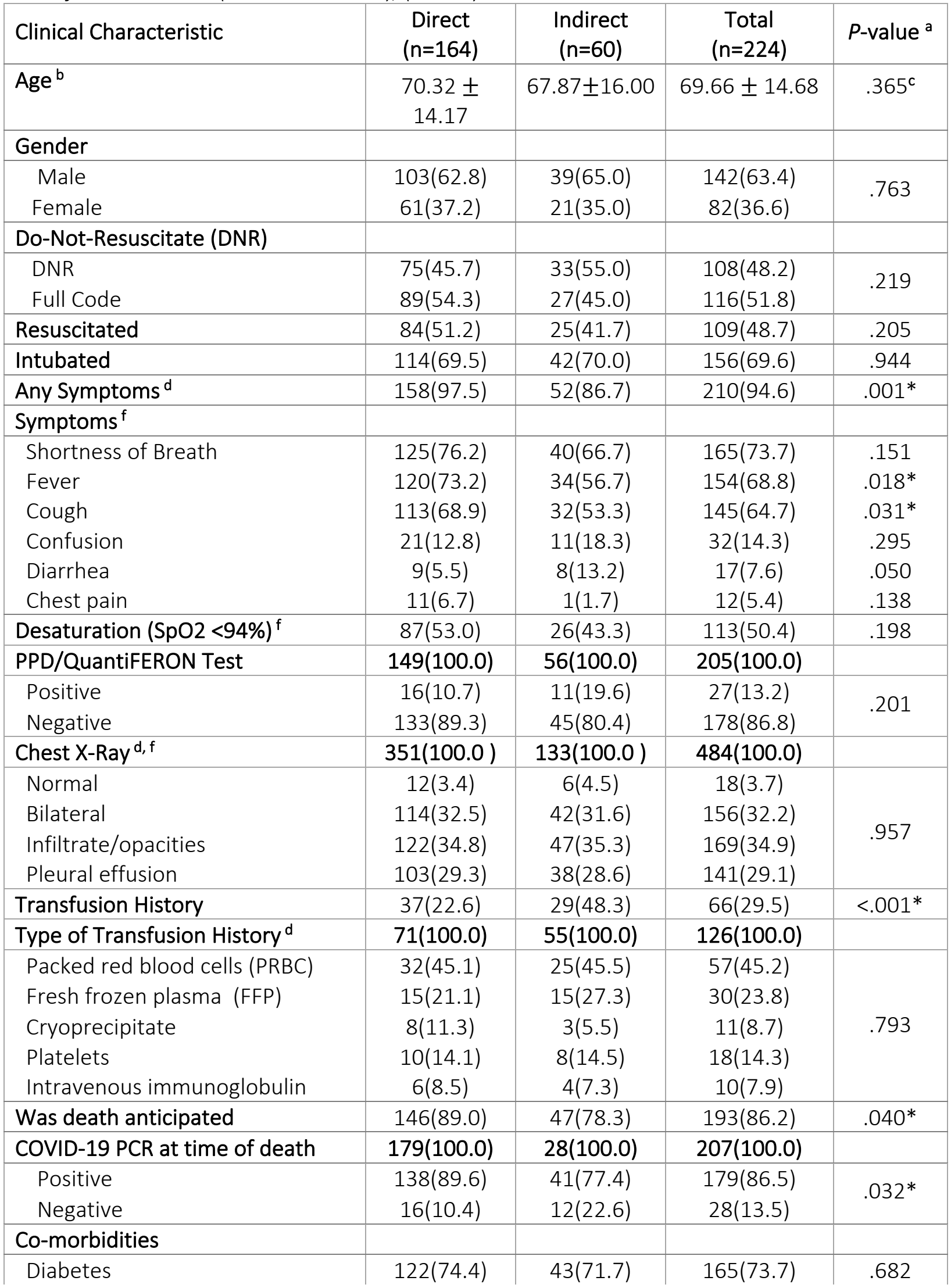




\begin{tabular}{|c|c|c|c|c|}
\hline Hypertension & 117(71.3) & $39(65.0)$ & 156(69.6) & .361 \\
\hline Chronic Kidney Failure & $40(24.4)$ & $16(26.7)$ & $56(25.0)$ & .728 \\
\hline Coronary Artery Disease & $39(23.8)$ & $13(21.7)$ & $52(23.2)$ & .740 \\
\hline Heart Failure & $16(9.8)$ & $9(15.0)$ & $25(11.2)$ & .270 \\
\hline Asthma & 19(11.6) & $5(8.3)$ & $24(10.7)$ & .486 \\
\hline Multiple sclerosis & 19(11.6) & $4(6.7)$ & $23(10.3)$ & .283 \\
\hline Atrial fibrillation & $14(8.5)$ & $8(13.3)$ & $22(9.8)$ & .285 \\
\hline On Dialysis & $14(8.5)$ & $3(5.0)$ & $17(7.6)$ & .376 \\
\hline Ischemic Stroke & $13(7.9)$ & $3(5.0)$ & $16(7.1)$ & .451 \\
\hline Thyroid Dysfunction & $11(6.7)$ & $5(8.3)$ & $16(7.1)$ & .676 \\
\hline Dementia & $4(2.4)$ & $8(13.3)$ & $12(5.4)$ & $.001^{*}$ \\
\hline Epilepsy & $3(1.8)$ & $3(5.0)$ & $6(2.7)$ & .194 \\
\hline Deep-vein thrombosis & $5(3.0)$ & $2(3.3)$ & $7(3.1)$ & .914 \\
\hline $\begin{array}{l}\text { Chronic obstructive pulmonary } \\
\text { disease (COPD) }\end{array}$ & $6(3.7)$ & $1(1.7)$ & $7(3.1)$ & .448 \\
\hline Cirrhosis & $4(2.4)$ & $0(0.0)$ & $4(1.8)$ & .222 \\
\hline Hepatitis C & $1(0.6)$ & $1(1.7)$ & $2(0.9)$ & .456 \\
\hline Hepatitis B & $1(0.6)$ & $1(1.7)$ & $2(0.9)$ & .456 \\
\hline Pulmonary embolism & $1(0.6)$ & $0(0.0)$ & $1(0.4)$ & .544 \\
\hline Obesity & $3(1.8)$ & $2(3.3)$ & $5(2.2)$ & .500 \\
\hline Co-infection & $160(100.0)$ & $58(100.0)$ & $218(100.0)$ & \\
\hline Positive & $37(23.1)$ & $27(46.6)$ & $64(29.4)$ & $<001 *$ \\
\hline Negative & $123(76.9)$ & $31(53.4)$ & $154(70.6)$ & \\
\hline If Co-infection positive ${ }^{d}$ & $40(100.0)$ & $26(100.0)$ & $66(100.0)$ & \\
\hline Bacterial & $19(47.5)$ & $17(65.4)$ & $36(54.5)$ & \\
\hline Fungal & $4(10.0)$ & $3(11.5)$ & $7(10.6)$ & .186 \\
\hline Viral & $17(42.5)$ & $6(23.1)$ & $23(34.8)$ & \\
\hline Complications & $153(100.0)$ & $53(100.0)$ & $206(100.0)$ & \\
\hline $\begin{array}{l}\text { Acute respiratory distress } \\
\text { syndrome }\end{array}$ & $116(75.8)$ & $24(64.2)$ & $150(72.8)$ & .100 \\
\hline Shock & $61(39.9)$ & $32(60.4)$ & $93(45.1)$ & $.010^{*}$ \\
\hline Acute kidney injury & $67(43.8)$ & $23(43.4)$ & $90(43.7)$ & .960 \\
\hline Sepsis / septic & $54(35.3)$ & $24(45.3)$ & $78(37.9)$ & .196 \\
\hline Secondary infections & $20(13.1)$ & $9(17.0)$ & $29(14.1)$ & .481 \\
\hline Cardiogenic shock & $6(3.9)$ & $8(15.1)$ & $14(6.8)$ & $.005^{*}$ \\
\hline Heart failure & $7(4.6)$ & $6(11.3)$ & $13(6.3)$ & .082 \\
\hline Atrial fibrillation & $9(5.9)$ & $3(5.7)$ & $12(5.8)$ & .953 \\
\hline Acute cardiac injury & $11(7.2)$ & $1(1.9)$ & $12(5.8)$ & .155 \\
\hline Myocardial infarction & $5(3.3)$ & $4(7.5)$ & $9(4.4)$ & .189 \\
\hline Ischemic stroke & $4(2.6)$ & $4(7.5)$ & $8(3.9)$ & .109 \\
\hline Acute pulmonary embolism & $4(2.6)$ & $4(7.5)$ & $8(3.9)$ & .109 \\
\hline Hypoxic encephalopathy & $3(2.0)$ & $3(5.7)$ & $6(2.9)$ & .167 \\
\hline $\begin{array}{l}\text { Reduced left ventricular ejection } \\
\text { fraction }\end{array}$ & $4(2.6)$ & $1(1.9)$ & $5(2.4)$ & .767 \\
\hline
\end{tabular}

${ }^{a}$ Chi-Square test, ${ }^{b}$ Mean $\pm S D,{ }^{c} T$-test, ${ }^{d}$ Reported one or more co-infection, chest $X$-ray and type of transfusion history, ${ }^{\mathrm{f}}$ at day of presentation. ${ }^{*} \mathrm{p}$-value $<0.05$ is significant. 


\section{Symptoms}

The most common presenting symptoms (at the day of presentation) were shortness of breath 165 (73.7\%), fever 154 (68.8\%), and cough 145 (64.7\%). In contrast, 113(50.4\%) of the cases had desaturation ( $\mathrm{SpO} 2<94 \%$ ) on the day of presentation. Mortality cases were classified as a direct or indirect cause of death from COVID-19. Around $73.2 \%$ of the cases were categorized as a direct cause of death from COVID-19, while 60(26.8\%) were indirect death from COVID-19. Direct mortality cases had significant symptoms at the day of presentation, fever and cough were significantly presented at the day of presentation ( $p$ values $0.001,0.018$, and 0.031 , respectively). While the indirect mortality cases had a significant positive co-infection and transfusion history ( $p$-values $<.001$ and $<.001$, respectively). [Table 2]

\section{Radiologic characteristics}

Table 2 shows no differences in chest $x$-ray at the day of presentation were observed among direct and indirect mortality cases. (34.9\%) of the cases showed lung infiltrate/opacities, and only (3.7\%) showed a normal chest $x$-ray on the day of presentation).

\section{Comorbidities}

Comorbidities were reported among 217 cases, and 143(63.8\%) of those cases reported multiple-comorbidity. Diabetes mellitus (DM) occurred in 165(73.7\%), and hypertension (HTN) in 156(69.6\%) as the most common comorbidities, followed by chronic kidney failure $56(25.0 \%)$, and coronary artery disease occurred in 52(23.2\%) of the cases. Asthma was present in 24(10.7\%) and COPD in 7(3.1\%) of the cases. However, hepatitis C and B occurred in $1.8 \%$ of the cases. [Table 2 and Fig 3]. 
Table 2 shows no differences in Comorbidities were observed among direct and indirect mortality cases, except for a significant difference in the indirect cause of death from COVID19 in dementia (p-values 0.001).

\section{Complications}

Table 2 and figure 4 shows the major COVID-19 mortality cases complications. The most common major complications were acute respiratory distress syndrome $150(72.8 \%)$, shock 93(45.1\%), acute kidney injury 90(43.7\%), and 78(37.9\%) had sepsis/septic. Eighteen of the cases had no documented major complications. There is a significant difference in the indirect cause of death from COVID-19 in cardiogenic shock and shock ( $p$-values 0.005 and 0.010, respectively). The death was anticipated among 193(86.2\%) and significant in the direct cohort (p-values 0. 040). [Table 2]

\section{Medication}

Figure 2 shows medication used for COVID-19 mortality cases. More than $80 \%$ of all COVID19 mortality cases were given DVT prophylaxis, 139(62.1\%) were given DVT treatment, and 127(56.7\%) were given Inotropes. 51(22.8\%) of COVID-19 mortality cases had been on ACEI/ARBS, while only 15(6.7\%) were on NSAID. 


\section{Table 3}

Biomarker Trends of Coronavirus Disease 2019 (COVID-19) Mortality Cases across (Day of presentation, Day 3-4, and 24-hr prior death) admitted to Prince Sultan Military Medical City, (March - July 2020), $(n=115)$

\begin{tabular}{|c|c|c|c|c|}
\hline \multirow{2}{*}{ Trends Biomarker } & \multicolumn{3}{|c|}{ Median( Minimum - Maximum) } & \multirow{2}{*}{ P-value } \\
\hline & Day of presentation & Day (3-4) & $\begin{array}{c}\text { 24-hr prior } \\
\text { death }\end{array}$ & \\
\hline Lymphocytes (\%) & $9.0(0.0-35.0)$ & $8.0(0.0-10.5)$ & $9.5(0.0-21.5)$ & .182 \\
\hline Serum Ferritin (pmol/L) & 700.5(37-9164) & $832(54-19864)$ & $\begin{array}{c}1081(15- \\
30356)\end{array}$ & $.004^{*}$ \\
\hline D-dimer $(\mathrm{mcg} / \mathrm{mL})$ & $1.53(0.18-20.0)$ & $1.83(0.30-20.0)$ & $\begin{array}{l}3.81(0.11- \\
20.0)\end{array}$ & $<.001^{*}$ \\
\hline $\begin{array}{l}\text { Serum Creatinine }(\mathrm{SrCr}) \\
(\mathrm{mol} / \mathrm{L})\end{array}$ & $104(18-1220)$ & $117(15-978)$ & 172(19-1627) & .059 \\
\hline $\begin{array}{l}\text { C-reactive protein(CRP) } \\
(\mathrm{mg} / \mathrm{l})\end{array}$ & $90(1-359)$ & $76(2-429)$ & $99(5-385)$ & .478 \\
\hline Procalcitonin (mcg/l) & $0.4(0.05-59.0)$ & $0.05(0.05-57.0)$ & $1.2(0.03-99.3)$ & $.004^{*}$ \\
\hline
\end{tabular}

a Wilcoxon Signed Ranks test. * p-value $<0.05$ is significant. 'Day (3-4)-24-hr prior death' durations has some missing values, due to a huge amount of patient died before they reach this stage.

\section{Trends Biomarker}

Table 3 and figure 5 shows the trends biomarker of COVID-19 mortality cases ( $n=115)$ admitted to Prince Sultan Military Medical City (PSMMC), Riyadh. COVID-19 Trends biomarker has been observed during the day of presentation, day (3-4), and 24-hr prior to death. The value for Serum Ferritin ( $\mathrm{pmol} / \mathrm{L}$ ) level has been increased ( $Z$ value $=-2.898, p$ value $=.004)$ from day of presentation 700.5(37-9164) to 24-hr prior death 1081(15-36356). As well as, the value of Procalcitonin $(\mathrm{mcg} / \mathrm{l})$ level has been increased $(Z$ value $=-2.864, p$ value $=.004)$ from day of presentation 0.4(0.05-59) to 24-hr prior death 1.2(0.03-99.3). While, the value for D-dimer $(\mathrm{mcg} / \mathrm{mL}$ ) level has been significantly increased (Z value $=-5.71, p$ value $<.001)$ from day of presentation $1.535(0.18-20)$ to 24 -hr prior death $3.815(0.11-20)$. [Table 3] 


\section{Table 4}

Logistic Regression for Risk Factors in Direct Mortality Cases and Cases admitted to intensive Care Unit with Coronavirus Disease 2019 (COVID-19) (n=224)

\begin{tabular}{|c|c|c|c|c|}
\hline \multirow[t]{2}{*}{ Variable } & Direct Death & & ICU Admission & \multirow{2}{*}{$P$-Value } \\
\hline & OR $(95 \% \mathrm{Cl})$ & & OR $(95 \% \mathrm{Cl})$ & \\
\hline Age & $0.98(0.97-1.00)$ & .270 & $1.01(0.99-1.03)$ & .270 \\
\hline Gender: Male & $0.91(0.49-1.68)$ & .763 & $1.92(1.09-3.37)$ & $.022 *$ \\
\hline Resuscitated & $1.47(0.80-2.67)$ & .206 & $0.99(0.57-1.71)$ & .978 \\
\hline ICU Admission & $1.21(0.66-2.23)$ & .524 & & \\
\hline Death was anticipated & $2.24(1.02-4.92)$ & $.044^{*}$ & $3.26(1.493-7.14)$ & $.003^{*}$ \\
\hline Desaturation $(\mathrm{SpO} 2<94 \%)^{a}$ & $1.47(0.81-2.68)$ & .199 & $1.77(1.02-3.06)$ & .042 \\
\hline Co-infection & $0.34(0.18-0.651)$ & $.001^{*}$ & $2.94(1.47-5.85)$ & $.002 *$ \\
\hline \multicolumn{5}{|l|}{ Comorbidities } \\
\hline Hypertension & $1.34(0.71-2.51)$ & .361 & $0.84(0.46-1.52)$ & .568 \\
\hline Diabetes & $1.14(0.59-2.22)$ & .682 & $1.26(0.68-2.32)$ & .450 \\
\hline Coronary Artery Disease & $1.12(0.55-2.29)$ & .740 & $0.90(0.47-1.70)$ & .751 \\
\hline Ischemic stroke & $1.63(0.44-5.95)$ & .455 & $0.72(0.25-2.02)$ & .540 \\
\hline COPD & $2.24(0.26-19.00)$ & .460 & $0.42(0.09-1.92)$ & .265 \\
\hline Asthma & $1.44(0.51-4.04)$ & .488 & $0.44(0.19-1.04)$ & .064 \\
\hline On dialysis & $1.77(0.49-6.4 .0)$ & .382 & $1.42(0.48-4.18)$ & .482 \\
\hline Multiple sclerosis & $1.83(0.59-5.63)$ & .289 & $1.36(0.53-3.45)$ & .518 \\
\hline \multicolumn{5}{|l|}{ Complications } \\
\hline $\begin{array}{l}\text { Acute respiratory distress } \\
\text { syndrome }\end{array}$ & $1.75(0.89-3.43)$ & .102 & $2.02(1.07-3.80)$ & $.029 *$ \\
\hline Acute kidney injury & $1.01(0.54-1.90)$ & .960 & $1.87(1.03-3.40)$ & $.039 *$ \\
\hline Shock & $0.43(0.23-0.82)$ & $.011^{*}$ & $2.72(1.47-5.01)$ & $.001^{*}$ \\
\hline Sepsis / septic & $0.65(0.34-1.24)$ & .198 & $2.92(1.52-5.60)$ & $.001^{*}$ \\
\hline Secondary infections & $0.73(0.31-1.73)$ & .482 & $2.85(1.03-7.84)$ & $.042 *$ \\
\hline Cardiogenic shock & $0.23(0.07-0.69)$ & $.009 *$ & $3.36(0.73-15-.47)$ & .119 \\
\hline
\end{tabular}

${ }^{a}$ At day of presentation, ${ }^{*}$ p-value $<0.05$ is significant, OR: odds ratio, $\mathrm{Cl}$ : confidence interval.

\section{Logistic regression for risk factors in all mortality cases}

Logistic regression for risk factors in all mortality cases with COVID-19 revealed that death was anticipated 2 times more likely among direct death from COVID-19 [OR 2.24 (Cl 1.024.92); $p=.044]$. Cases with a history of COPD are 2 times more likely to die directly from COVID-19 [OR 2.24 (Cl 0.26-19.00); $p=.460]$. 
As well as, cases with a history on dialysis [OR 1.77 ( $\mathrm{Cl}$ 0.49-6.4.0); $\mathrm{p}=.382$ ], ischemic stroke [OR 1.63 (Cl 0.44-5.95); $\mathrm{p}=.455]$, asthma [OR 1.44 (Cl 0.51-4.04); $\mathrm{p}=.488$ ], hypertension [OR $1.34(\mathrm{Cl} 0.71-2.51) ; p=.361$ ], diabetes [OR $1.14(\mathrm{Cl} 0.59-2.22) ; p=.682$ ], and coronary artery disease[OR 1.12 (CI 0.55-2.29); $\mathrm{p}=.740$ ] are more likely to died directly from COVID-19. A direct mortality cases from COVID-19 are more likely to develop acute respiratory distress syndrome and acute kidney injury [OR 1.75 (Cl 0.89-3.43); p=.102], [OR 1.01 (Cl 0.54-1.90); $p=.960]$ respectively. [Table 4]

Predictors for COVID-19 mortality cases admitted to ICU using logistic regression for risk factors revealed that death was anticipated 3 times more likely among ICU cases [OR 3.26 (CI 1.11-13.16); $\mathrm{p}=.033]$. COVID-19 mortality cases with a history of co-infection are 2 times more likely to admitted to ICU [OR 2.94 (CI 1.47-5.85); $\mathrm{p=}=.002$ ], as well as, cases with a factors such as male gender [OR 1.92 (Cl 0.99-1.03); p=.002], age [OR 1.01 (Cl 0.99-1.03); $\mathrm{p}=.270$ ], multiple sclerosis [OR $1.42(\mathrm{Cl} 0.53-3.45) ; \mathrm{p}=.518$ ], on dialysis [OR $1.36(\mathrm{Cl} 0.48-$ 4.18); $\mathrm{p}=.482$ ], diabetes [OR $1.26(\mathrm{Cl} 0.68-2.32) ; \mathrm{p}=.450$ ], are more likely to admitted to ICU. [Table 4]

\section{Case Fatality Rate (CFR) and ICU Beds Occupancy Rate}

Figure 6 shows the CFR of COVID -19 stratified by month and the average ICU bed occupancy rate during (April- July 2020) for Riyadh, Southern Region, Taif, Al-Kharj, Jeddah, and Northwest Region. There was an association between COVID-19 CFR increasing and the average of ICU beds occupancy rate in Riyadh hospital during May-July 2020 (CFR: 1.10\%, $1.16 \%$, and $2.54 \%$, respectively) and (ICU beds occupancy rate; $110 \%, 130 \%$, and $150 \%$, respectively). As well as, Al-Kharj region hospital (CFR: 2.70\%, 3.77\%, and 4.27\%, respectively) 
and (ICU beds occupancy rate: 110\%, 130\%, and 150\%, respectively) during April-July 2020. [Figure 6]

\section{Kaplan-Meier Analysis of Survival of Mortality Cases}

$30 \%$ of overall COVID-19 mortalities ( $n=424)$ occurred in the first 24 hours of hospital admission, while $50 \%$ of the mortalities occurred on day 10 of admission. The survival analysis of COVID-19 mortality cases shows a significant difference between the direct and indirect cause of death from COVID-19 in the survival and cases admitted to ICU or general ward (p-values 0.012 and <.001, respectively). However, there were no significant differences in the survival analysis of COVID-19 mortality cases (DNR - Full Code) ( $p$-values 0. 525). [Fig 7] 


\section{Discussion}

To our knowledge, this multi-center study is one of the few, if not the first study to comprehensively present the clinical characteristics of COVID-19 mortality cases among the Saudi population. Studies describing the demographic and clinical characteristics of COVID-19 mortality in the Middle East and the Gulf Cooperation Council (GCC) countries, in particular, are relatively scarce.(15)(9)(16)

All the laboratory-confirmed COVID-19 mortality cases admitted to MSD hospitals from all Saudi Arabia regions during March-July 2020 were included in this study. The mean age group was $69.66 \pm 14.68$ years, compared to the international mean age $56.6 \pm 13.97$ years was in the Pakistani cohort, and the median age in an Italian and Spain cohorts 78 years.(17) (18) This variation might be attributed to differences in the population age group density. Along with a recent meta-analysis, after screening 516 studies across the globe, 43 studies from 12 countries. Reported a significant variation in the clinical characteristics in patients diagnosed with COVID-19 globally. In-hospital mortality is similar between America and Europe, but considerably higher than in Asia. COVID-19 mortality in America and Europe were older compared to their Asian counterparts.(19) The study data added to the fact that advanced age is one of the risk factors of mortality. Death was also significantly higher in males than in females, as described in other studies.(17)'(20)

Majority of the deceased patients in our cohort had blood group B (48.7\%) followed by $O$ group (30.4\%). In contrast, most of the papers mentioned the blood group preponderance for acquiring COVID-19 infection was blood group A as the dominant one; however, all these papers show different types of severity mild, moderate, and severity. (21)'(22) A paper by Adiah et al. mentioned groups $A B$ and $B+A B$ to be significantly associated with increased risk 
to develop COVID-19 were associated with increased risk of death in deceased cases.(23) A meta-analysis by Pourali states that individuals with blood group A are at higher risk for COVID-19 infection while those with blood group O are at a lower risk.(24)

Consistent with previous reports(17)-(25), the most common presented comorbidity among mortality cases were diabetes (73.7\%) and hypertension (69.6\%). As diabetes is a highly correlated factor for virus-related deaths.(26)'(5) With a high impact of diabetes on mortality up to the two-fold risk of death as shown by Kumar et al. meta-analysis.(27) This pattern of associations is consistent with a large deaths record of more than 17 million COVID-19 cases from New England Institute Hospitals NIH.(28)

Un surprisingly, people with COPD are at risk of severe COVID-19, our data revealed that cases with COPD have two folds mortality risk, yet it was not clear if these cases were on inhaled corticosteroids or long acting beta agonists prior to the index date of death as a cardinal correlation between exposure to inhaled corticosteroids and COPD in COVID 19 deaths from England records.(29)

Given the different prevalence of obesity across the world, some data have suggested that pre-existing obesity is one of the underlying risk factors of COVID19 mortality that is of the same impact as Swine flu (H1N1).(30) However, in our cohort only (2.2\%) of the mortality cases had a pre-existing obesity.

Along with a recent report, a clear burden of COVID-19 infection and multiple organ dysfunction has been observed on lung, heart, followed by the kidney.(31) Acute respiratory 
distress syndrome (ARDS) was the main direct COVID-19 related complication. As a result of progressive inflammatory and thrombogenesis cascades, substantial indirect complications were noted in particularly cardiac injury, as was reported in up to $19.7 \%$ of the Chines cohort.(32) ARDS secondary to COVID Pneumonia has been the most frequent complication in most case series. Diffuse Alveolar damage is the primary event followed by thrombotic microangiopathy and some severe cases ending up in DIC like picture without any evidence of bacterial superinfection. Dilated pulmonary vessels are a frequent finding in ARDS secondary to COVID in contrast to ARDS secondary to other causes.(33)

Indeed, different range of co infection have been reported from different parts of the world, recent metanalysis by Lansbury L etl states that $14 \%$ of bacterial co infection in COVID 19 admitted to the ICU.(34)'(35) Interestingly, the postmortem data showed up to $37 \%$ of COVID 19 deaths had pulmonary histopathological data consistent with superimposed bacterial pneumonia.(36)

In order to screen the biochemical indicators that are meaningful for the diagnosis of disease progression, the laboratory test results of all the mortality cases from PSMMC hospital $(n=115)$ were included. Along with a recent report, the rising of serum ferritin, Procalcitonin, $\mathrm{CRP}$, and D-dimer levels can be used as indicators of disease progression.(31) It has been reported in a French paper that CRP and high BUN are associated with cytokine release syndrome driven increased mortality.(37) In our study, rising ferritin, D-dimer, and procalcitonin are associated with mortality. Most inflammatory markers are acute phase reactants that are not specific for severe COVID pneumonia. Qin et al. found a significant association between increased CRP and severe prognosis of the disease.(38) Variable studies 
have shown D-dimer as an effective predictor for mortality of COVID-19. Its role in acute infections and thrombogenic states was known from before.(39) Asghar et al. have written in their paper that LDH, D-dimer, $\mathrm{PCT}$, and ferritin have a role in predicting the severity of COVID -19 Pneumonia.(40)

It is worth mentioning this study addressed a very important observation of the longitudinal association of the ICU bed occupancy and the fatality rate all over the hospitals with the highest rate of bed occupancy in Riyadh city, which is the capital city that accommodates the largest population. Its center was considered the biggest tertiary referral center from all other MSD hospitals, with a corresponding fatality rate of $2.54 \%$. However, the highest fatality rate was observed from the southern region hospital (Khamis Mushait city), which reached $4.88 \%$, as their ICU occupancy beds have increased by $10 \%$ above their capacity. Notably, the western region hospitals represented by Ttaif and Jeddah cities seem to cope with the pandemic with an adequate ICU bed occupancy matched to their capacity $(95 \%, 100 \%$ subsequently) with the lower fatality rate $(0.93 \%, 0.18 \%$ respectively) that correlation between the mortality and the health care burden have been reported previously from China and different parts of the world historically.(41)'(42)

The study findings suggested that, the main cause of mortality in COVID-19 is attributed either to acute respiratory failure or acute thrombosis. Patients with comorbidities are at higher risk for contracting COVID-19, and some laboratory tests can predict disease progression and death, as the serum ferritin, Procalcitonin, CRP, and D-dimer levels can be used as indicators of disease progression. 
The study has some limitations. First, the design was retrospective. Second, some cases had incomplete data on laboratory tests, and complications, given the variation in electronic databases' structure across different MSD hospitals. Third, there was a lack of proper disease severity scoring. Fourth, although the study is multi-center, the number of mortalities was small. Therefore, future studies with larger sample sizes are needed. 


\section{Conclusion}

The prevalence of underlying diseases DM and HTN is high among COVID-19 mortality cases in Saudi Arabia. Multiple organ dysfunction can be observed, the most common organ damage, lungs, heart, followed by the kidney. The rising of serum ferritin, Procalcitonin, CRP, and D-dimer levels can be used as indicators of disease progression.

This study highlights the significant burden of the COVID-19 outbreak, particularly in patients' health and the healthcare system. This study's clinical implication provides insight into the major death indicators among COVID-19 patients in Saudi Arabia. These indicators may help physicians triage patients, identify critically ill patients, and prioritize ICU admissions by identifying high-risk medical and clinical indicators. 


\section{List of abbreviations}

Coronavirus Disease 2019 - (COVID-19)

Kingdom of Saudi Arabia - (KSA)

Armed Forces Medical Services Hospitals - (MSD)

World Health Organization - (WHO)

Prince Sultan Military Medical City - (PSSMC)

Polymerase chain reaction - (PCR)

Do-Not-Resuscitate - (DNR)

Intensive Care Unit - (ICU)

Diabetes mellitus - (DM)

Hypertension - (HTN)

Chronic obstructive pulmonary disease - (COPD)

C-Reactive Protein - (CRP)

Serum Creatinine - $(\mathrm{SrCr})$

Odds ratio - (OR)

Confidence interval - $(\mathrm{Cl})$

Swine flu - (H1N1)

Acute respiratory distress syndrome - (ARDS) 
Fig 1 Distribution of Coronavirus disease 2019 (COVID-19) mortality cases

(A) Distribution of Coronavirus disease 2019 (COVID-19) mortality cases stratified by age and cause of death from (Direct Indirect), (B) and date of death from COVID-19 stratified by Cause of death (Direct Indirect). ( $n=224)$

(A)

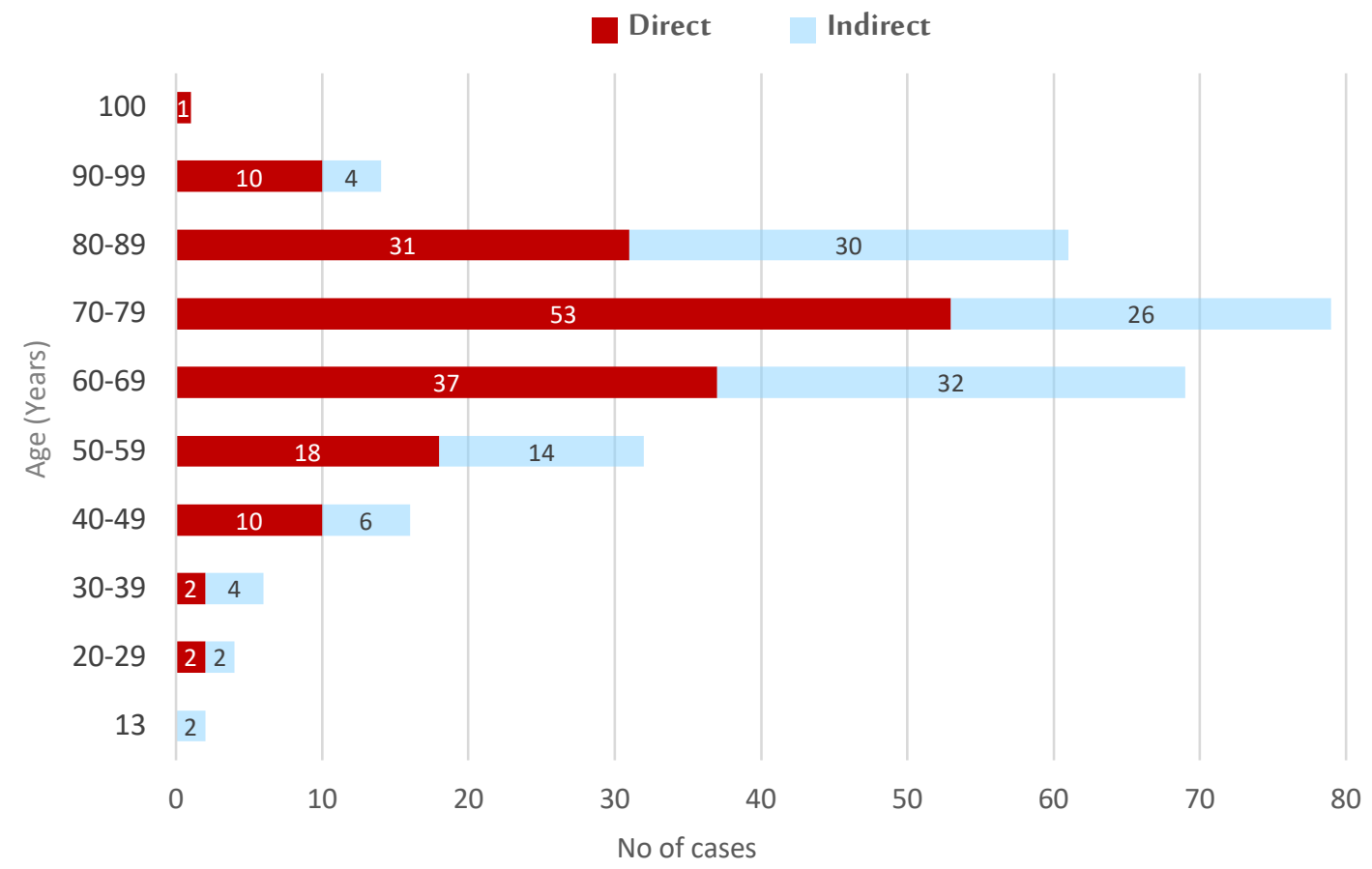

(B)

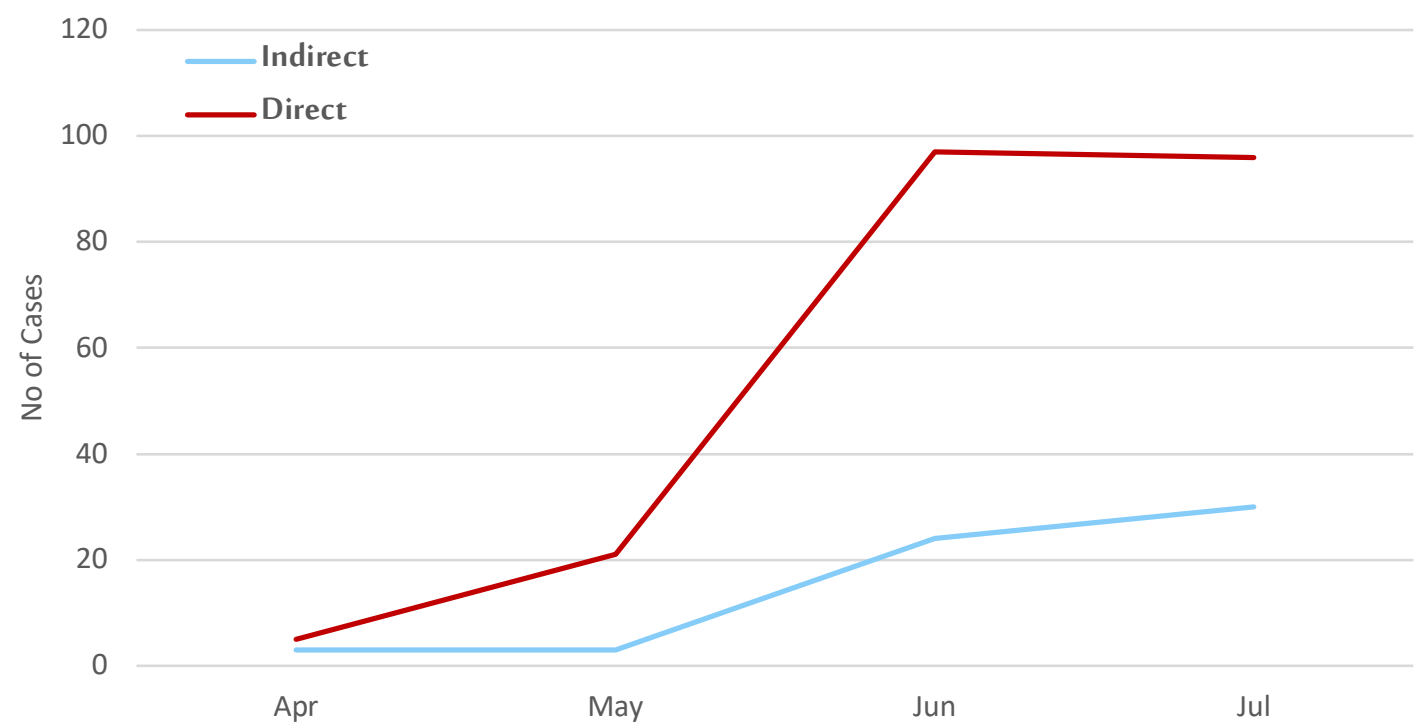


Fig 2 Medication of Coronavirus disease 2019 (COVID-19) mortality cases admitted to Armed Forces Medical Services Hospitals (MSD), $(n=224)$

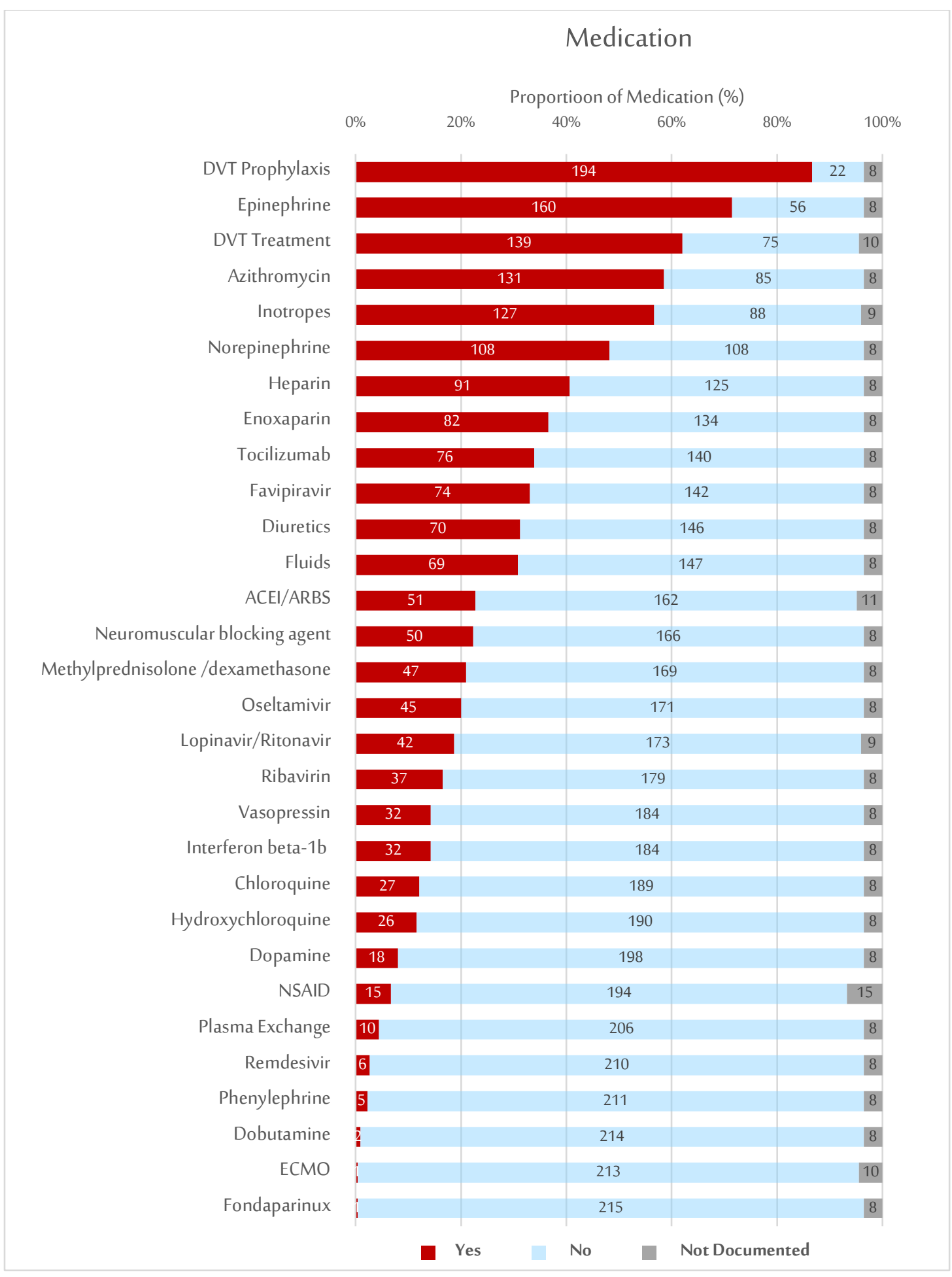


Fig 3 Co-morbidities of Coronavirus Disease 2019 (COVID-19) Mortality Cases Admitted to Armed Forces Medical Services Hospitals (MSD) ), $(n=224)$

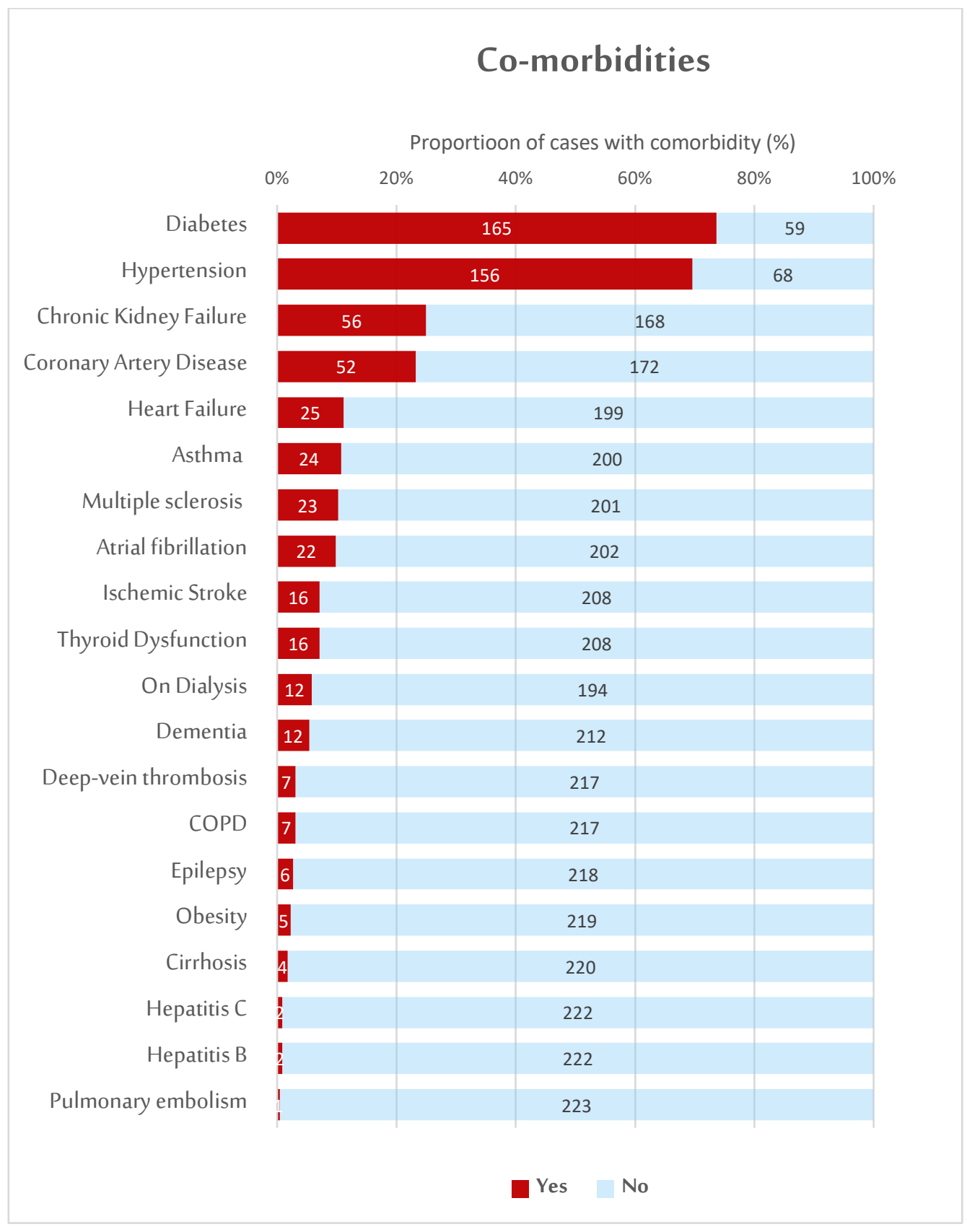


Fig 4 Complications of Coronavirus Disease 2019 (COVID-19) Mortality Cases admitted to Armed Forces Medical Services Hospitals (MSD) ), $(n=224)$

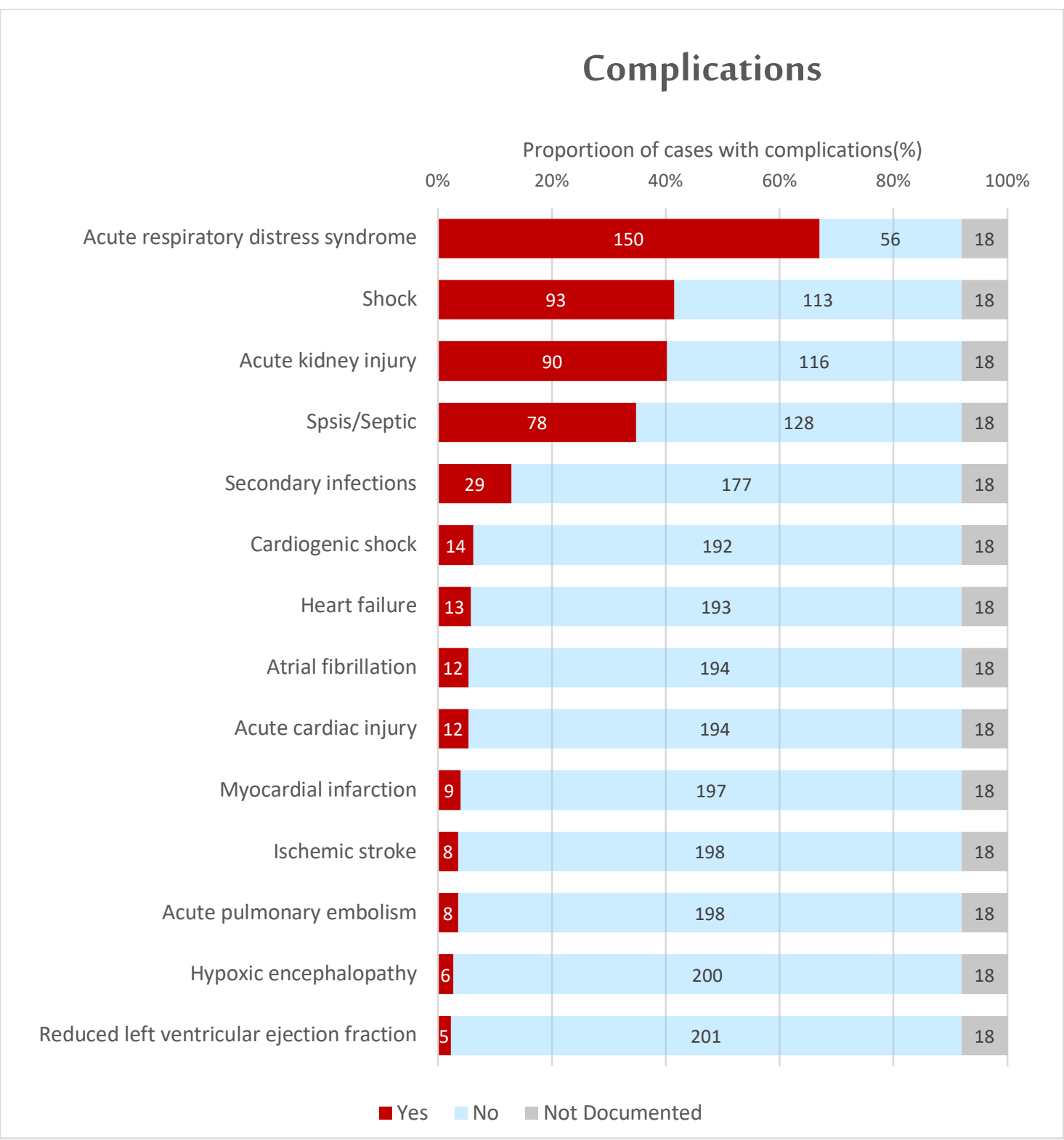


Fig 5 Biomarker Trends of Coronavirus Disease 2019 (COVID-19) Mortality Cases Admitted to Prince Sultan Military Medical City, $(n=115)$
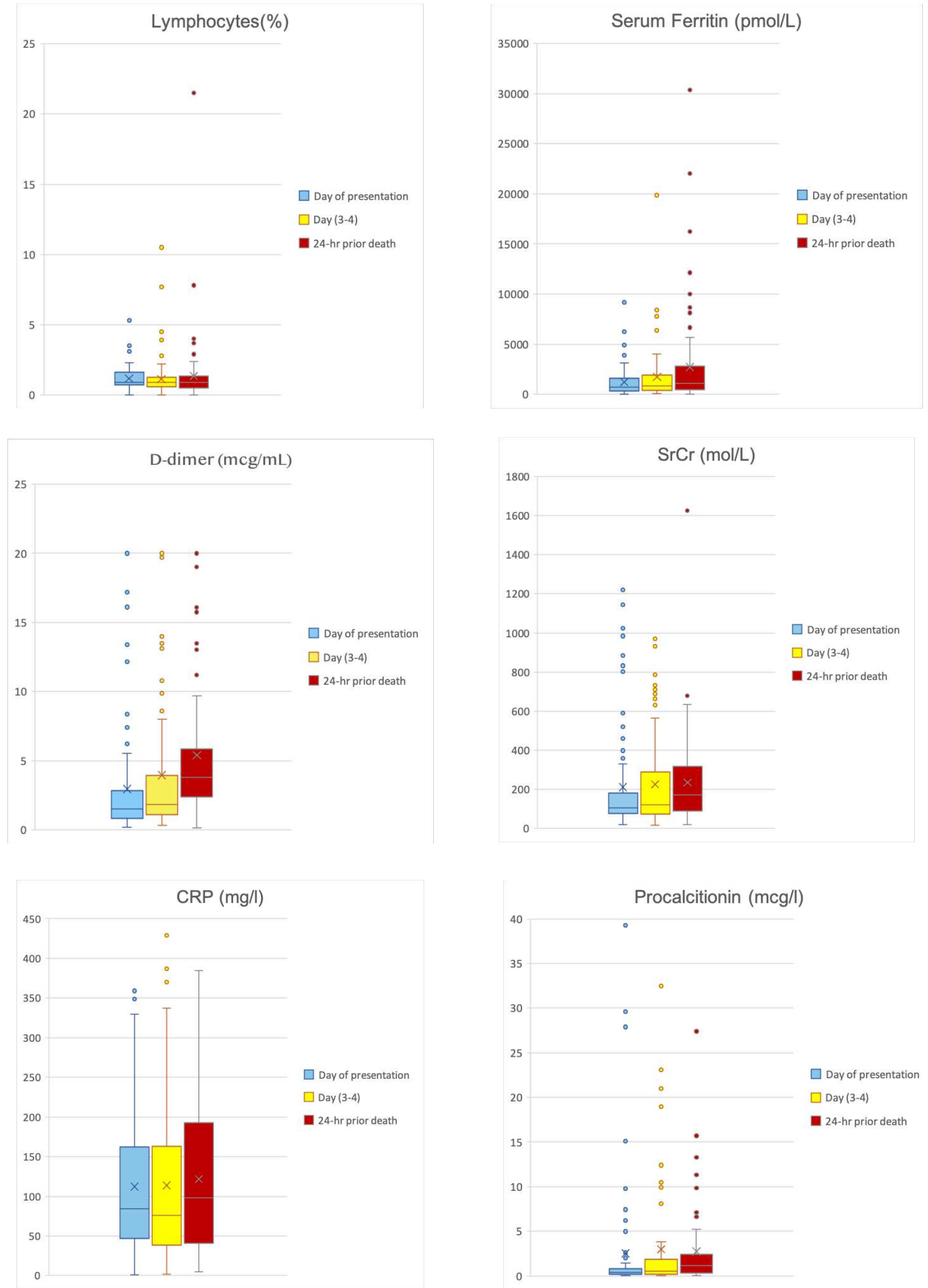
Fig 6 Case Fatality Rate (CFR) of Coronavirus disease 2019 (COVID-19) Stratified by Month and The Average of ICU Beds Occupancy Rate, for the highest 6 Cities in KSA (April- July 2020). (A)Riyadh, (B) Khamis Mushait, (C)Taif, (D) Al-Kharj, (E)Jeddah, (F) Tabuk.

(A)

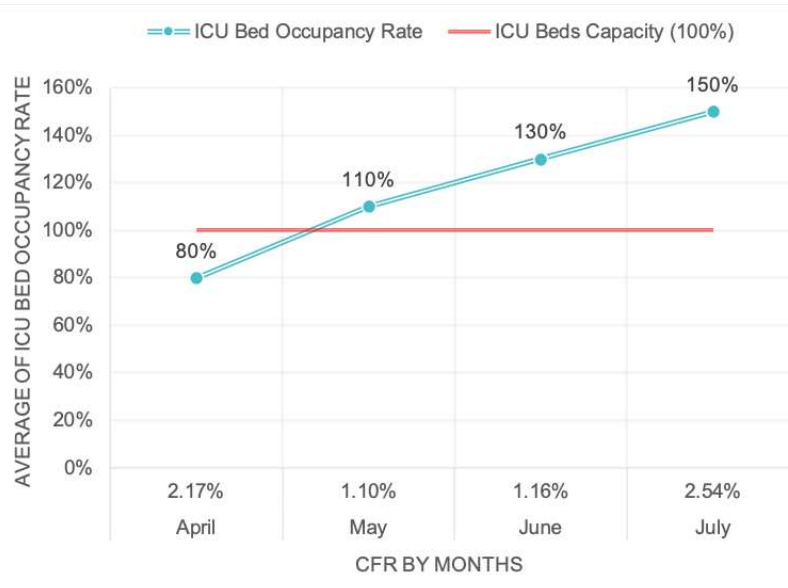

(C)

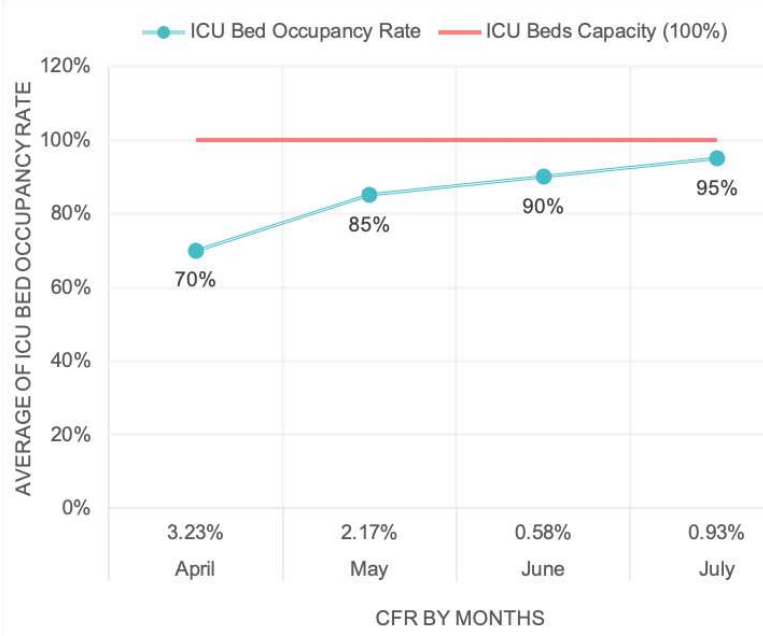

(E)

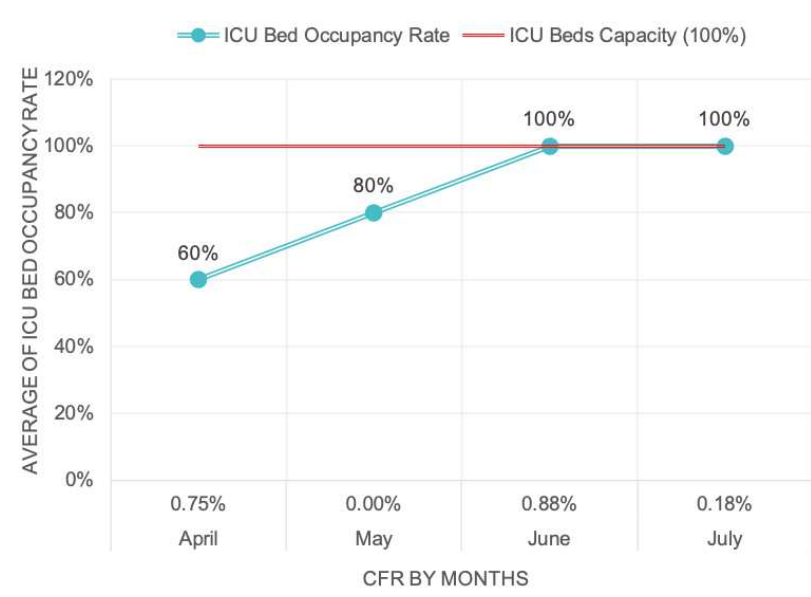

(B)

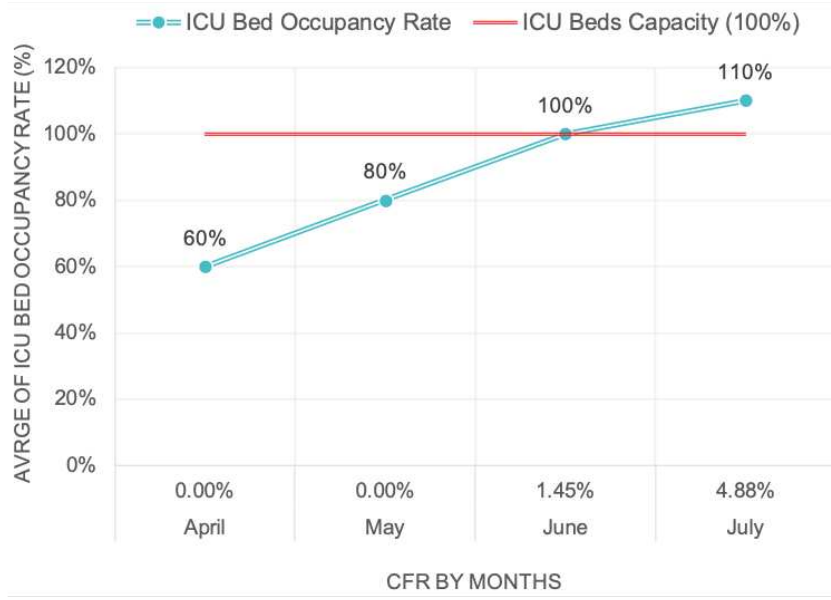

(D)

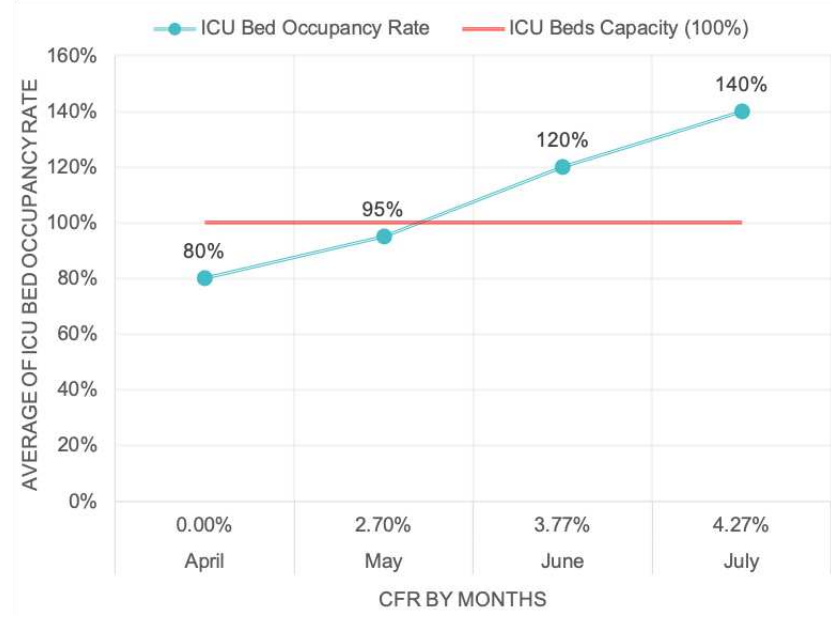

(F)

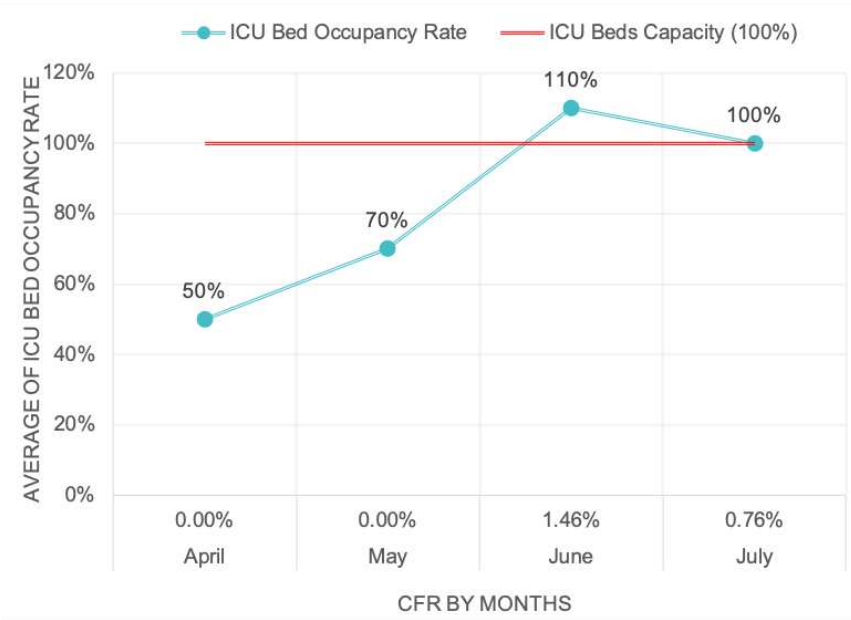


Fig 7 Kaplan-Meier Analysis of Survival (Time to death) of Coronavirus Disease 2019 (COVID19) Mortality Cases

(A) Analysis of Survival of All COVID-19 Mortality Cases. (B) COVID-19 Mortality Cases Stratified by (Direct-Indirect) as a cause of death. (C) COVID-19 Mortality Cases Stratified by (Intensive Care Unit/General Ward) admission. (D) COVID-19 Mortality Cases Stratified by (DNR - Full Code).

(A)

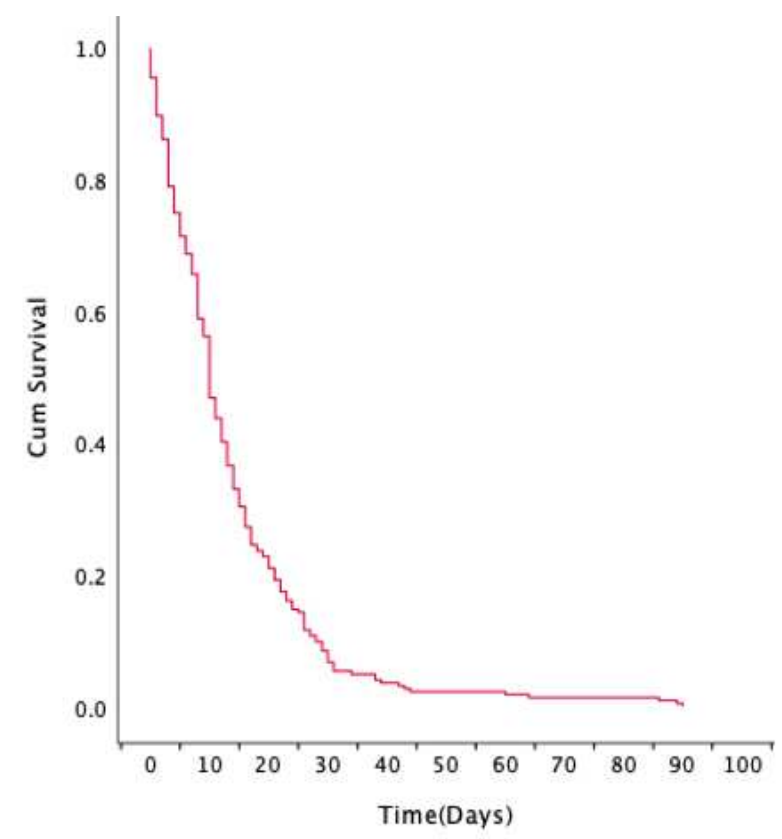

(C)

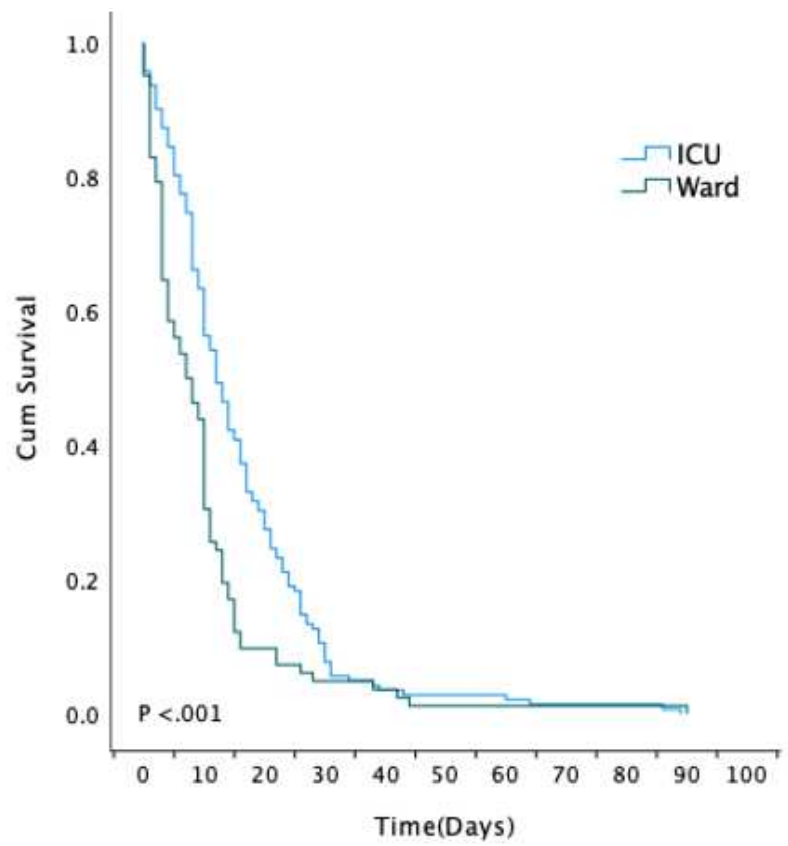

(B)

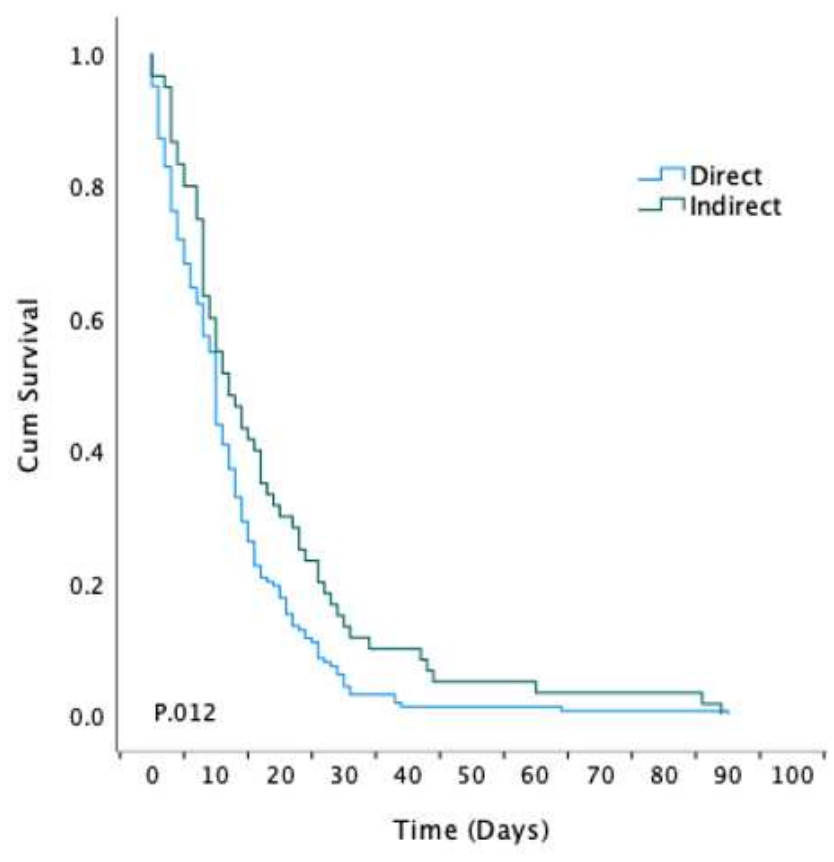

(D)

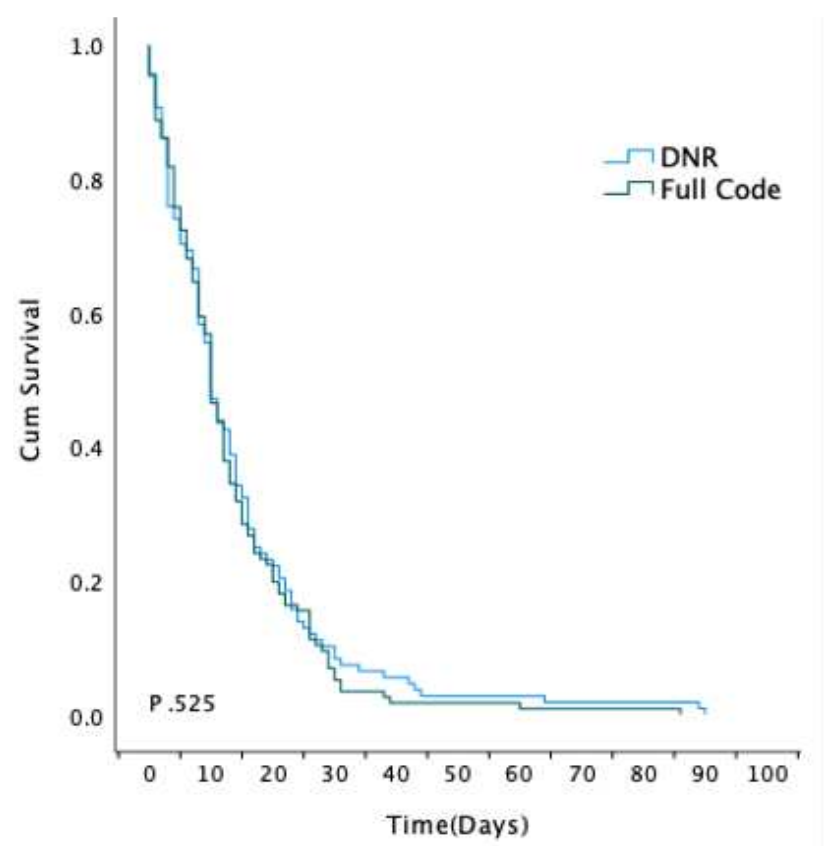




\section{Ethics approval and consent to participate}

Ethical approval obtained from the Armed Forces Medical Services Scientific Research

Center, Central Research Ethics Committee (Approval number 2020-012).

\section{Consent for publication}

Not applicable

\section{Availability of data and materials}

The datasets used and/or analysed during the current study are available from the corresponding author on reasonable request.

\section{Competing interests}

The authors declare that they have no competing interests

\section{Funding}

Not applicable

\section{Authors' contributions}

RS analyzed all the data and interpreted the result, and was a major contributor in writing the manuscript. HS provided data regarding MSD hospitals ICU occupancy rate, calculated CFR and revise the manuscript. $A B$ and KK provided data on PSMMC cases regarding lab biomarkers and was a major contributor in writing the discussion section.

\section{Acknowledgements}

None 


\section{References:}

1. Saudi Ministry of Health. Coronavirus Disease COVID-19 Guidelines, v1.3. 2020;1-44. Available from: https://www.moh.gov.sa/Ministry/MediaCenter/Publications/Documents/CoronavirusDisease-2019-Guidelines-v1.2.pdf

2. World Health Organization. Clinical management of severe acute respiratory infection when novel coronavirus (nCoV) infection is suspected. Who. 2020;

3. WHO, Aylward, Bruce (WHO); Liang W (PRC). Report of the WHO-China Joint Mission on Coronavirus Disease 2019 (COVID-19). WHO-China Jt Mission Coronavirus Dis 2019. 2020;

4. Guan W, Ni Z, Hu Y, Liang W, Ou C, He J, et al. Clinical Characteristics of Coronavirus Disease 2019 in China. N Engl J Med. 2020;382(18):1708-20.

5. Docherty AB, Harrison EM, Green CA, Hardwick HE, Pius R, Norman L, et al. Features of 20133 UK patients in hospital with covid-19 using the ISARIC WHO Clinical Characterisation Protocol: Prospective observational cohort study. BMJ. 2020;

6. Liang LL, Tseng $\mathrm{CH}, \mathrm{Ho} \mathrm{HJ}, \mathrm{Wu} \mathrm{CY}$. Covid-19 mortality is negatively associated with test number and government effectiveness. Sci Rep. 2020;

7. Chen T, Wu D, Chen H, Yan W, Yang D, Chen G, et al. Clinical characteristics of 113 deceased patients with coronavirus disease 2019: Retrospective study. BMJ. 2020;

8. Ministry of Health (MOH). Information about COVID-19 - Coronavirus in Saudi Arabia. 2020.

9. Alsofayan YM, Althunayyan SM, Khan AA, Hakawi AM, Assiri AM. Clinical characteristics of COVID-19 in Saudi Arabia: A national retrospective study. J Infect Public Health. 2020;

10. World Health Organization. WHO Coronavirus disease (COVID-19) technical guidance: Laboratory testing for 2019-nCoV in humans. Who. 2020.

11. Harrington RA. Case fatality rate. Encycl Br.

12. Singer M, Deutschman CS, Seymour C, Shankar-Hari M, Annane D, Bauer M, et al. The third international consensus definitions for sepsis and septic shock (sepsis-3). JAMA - Journal of the American Medical Association. 2016.

13. World Health Organization W. International guidelines for certification and classification (coding) of COVID-19 as cause of death. Based on ICD International Statistical Classification of Diseases. 2020;(April):14.

14. For P, Council SH. NATIONAL POLICY AND PROCEDURE FOR DO-NOT-RESUSCITATE (DNR) STATUS. 2017;8(January):1-14.

15. Shabrawishi M, Al-Gethamy MM, Naser AY, Ghazawi MA, Alsharif GF, Obaid EF, et al. Clinical, radiological and therapeutic characteristics of patients with COVID-19 in Saudi Arabia. PLoS One. 2020;

16. Abohamr SI, Abazid RM, Aldossari MA, Amer HA, Badhawi OS, Aljunaidi OM, et al. Clinical characteristics and in-hospital mortality of covid-19 adult patients in saudi arabia. Saudi Med J. 2020;

17. Shahid R, Umar M, Zafar RB, Zeb S, Ambreen S, Akram MO. Comorbidity of COVID-19 related Fatalities in Tertiary Care Hospitals of Rawalpindi, Pakistan. J Rawalpindi Med Coll. 2020;24(Supp-1).

18. Biagi A, Rossi L, Malagoli A, Zanni A, Sticozzi C, Comastri G, et al. Clinical and epidemiological characteristics of 320 deceased patients with COVID-19 in an Italian Province: A retrospective observational study. J Med Virol. 2020;

19. Goel S, Jain T, Hooda A, Malhotra R, Johal G, Masoomi R, et al. Clinical Characteristics and InHospital Mortality for COVID-19 Across The Globe. Cardiol Ther. 2020;

20. Berenguer J, Ryan P, Rodríguez-Baño J, Jarrín I, Carratalà J, Pachón J, et al. Characteristics and predictors of death among 4035 consecutively hospitalized patients with COVID-19 in Spain. Clin Microbiol Infect. 2020;

21. Hultström M, Persson B, Eriksson O, Lipcsey M, Frithiof R, Nilsson B. Blood type A associates with critical COVID-19 and death in a Swedish cohort. Critical Care. 2020. 
22. Zietz M, Zucker J, Tatonetti NP. Associations between blood type and COVID-19 infection, intubation, and death. Nat Commun. 2020;

23. Ad'hiah AH, Allami RH, Mohsin RH, Abdullah MH, AL-Sa'ady AJR, Alsudani MY. Evaluating of the association between ABO blood groups and coronavirus disease 2019 (COVID-19) in Iraqi patients. Egypt J Med Hum Genet. 2020;

24. Pourali F, Afshari M, Alizadeh-Navaei R, Javidnia J, Moosazadeh M, Hessami A. Relationship between blood group and risk of infection and death in COVID-19: a live meta-analysis. New Microbes New Infect. 2020;

25. Grasselli G, Greco M, Zanella A, Albano G, Antonelli M, Bellani G, et al. Risk Factors Associated with Mortality among Patients with COVID-19 in Intensive Care Units in Lombardy, Italy. JAMA Intern Med. 2020;

26. Garg S, Kim L, Whitaker M, O'Halloran A, Cummings C, Holstein R, et al. Hospitalization Rates and Characteristics of Patients Hospitalized with Laboratory-Confirmed Coronavirus Disease 2019 - COVID-NET, 14 States, March 1-30, 2020. MMWR Morb Mortal Wkly Rep. 2020;

27. Kumar A, Arora A, Sharma P, Anikhindi SA, Bansal N, Singla V, et al. Is diabetes mellitus associated with mortality and severity of COVID-19? A meta-analysis. Diabetes Metab Syndr Clin Res Rev. 2020;

28. Williamson EJ, Walker AJ, Bhaskaran K, Bacon S, Bates C, Morton CE, et al. Factors associated with COVID-19-related death using OpenSAFELY. Nature. 2020;

29. Schultze A, Walker AJ, MacKenna B, Morton CE, Bhaskaran K, Brown JP, et al. Risk of COVID19-related death among patients with chronic obstructive pulmonary disease or asthma prescribed inhaled corticosteroids: an observational cohort study using the OpenSAFELY platform. Lancet Respir Med. 2020;

30. Dietz W, Santos-Burgoa C. Obesity and its Implications for COVID-19 Mortality. Obesity. 2020.

31. Li X, Wang L, Yan S, Yang F, Xiang L, Zhu J, et al. Clinical characteristics of 25 death cases with COVID-19: A retrospective review of medical records in a single medical center, Wuhan, China. Int J Infect Dis. 2020;

32. Shi S, Qin M, Shen B, Cai Y, Liu T, Yang F, et al. Association of Cardiac Injury with Mortality in Hospitalized Patients with COVID-19 in Wuhan, China. JAMA Cardiol. 2020;

33. Gibson PG, Qin L, Puah SH. COVID-19 acute respiratory distress syndrome (ARDS): clinical features and differences from typical pre-COVID-19 ARDS. Medical Journal of Australia. 2020.

34. Lai CC, Wang CY, Hsueh PR. Co-infections among patients with COVID-19: The need for combination therapy with non-anti-SARS-CoV-2 agents? Journal of Microbiology, Immunology and Infection. 2020.

35. Lansbury L, Lim B, Baskaran V, Lim WS. Co-infections in people with COVID-19: a systematic review and meta-analysis. J Infect. 2020;

36. Calabrese F, Pezzuto F, Fortarezza F, Hofman P, Kern I, Panizo A, et al. Pulmonary pathology and COVID-19: lessons from autopsy. The experience of European Pulmonary Pathologists. Virchows Archiv. 2020.

37. Oussalah A, Gleye S, Urmes IC, Laugel E, Barbé F, Orlowski S, et al. The spectrum of biochemical alterations associated with organ dysfunction and inflammatory status and their association with disease outcomes in severe COVID-19: A longitudinal cohort and time-series design study. EClinicalMedicine. 2020;

38. Qin C, Zhou L, Hu Z, Zhang S, Yang S, Tao Y, et al. Dysregulation of immune response in patients with coronavirus 2019 (COVID-19) in Wuhan, China. Clin Infect Dis. 2020;

39. Zhou F, Yu T, Du R, Fan G, Liu Y, Liu Z, et al. Clinical course and risk factors for mortality of adult inpatients with COVID-19 in Wuhan, China: a retrospective cohort study. Lancet. 2020;

40. Asghar MS, Haider Kazmi SJ, Ahmed Khan N, Akram M, Hassan M, Rasheed U, et al. Poor Prognostic Biochemical Markers Predicting Fatalities Caused by COVID-19: A Retrospective Observational Study From a Developing Country. Cureus. 2020;

41. Ji Y, Ma Z, Peppelenbosch MP, Pan Q. Potential association between COVID-19 mortality and 
health-care resource availability. The Lancet Global Health. 2020.

42. Bambra C, Riordan R, Ford J, Matthews F. The COVID-19 pandemic and health inequalities. Journal of Epidemiology and Community Health. 2020. 


\section{Figures}

(A)

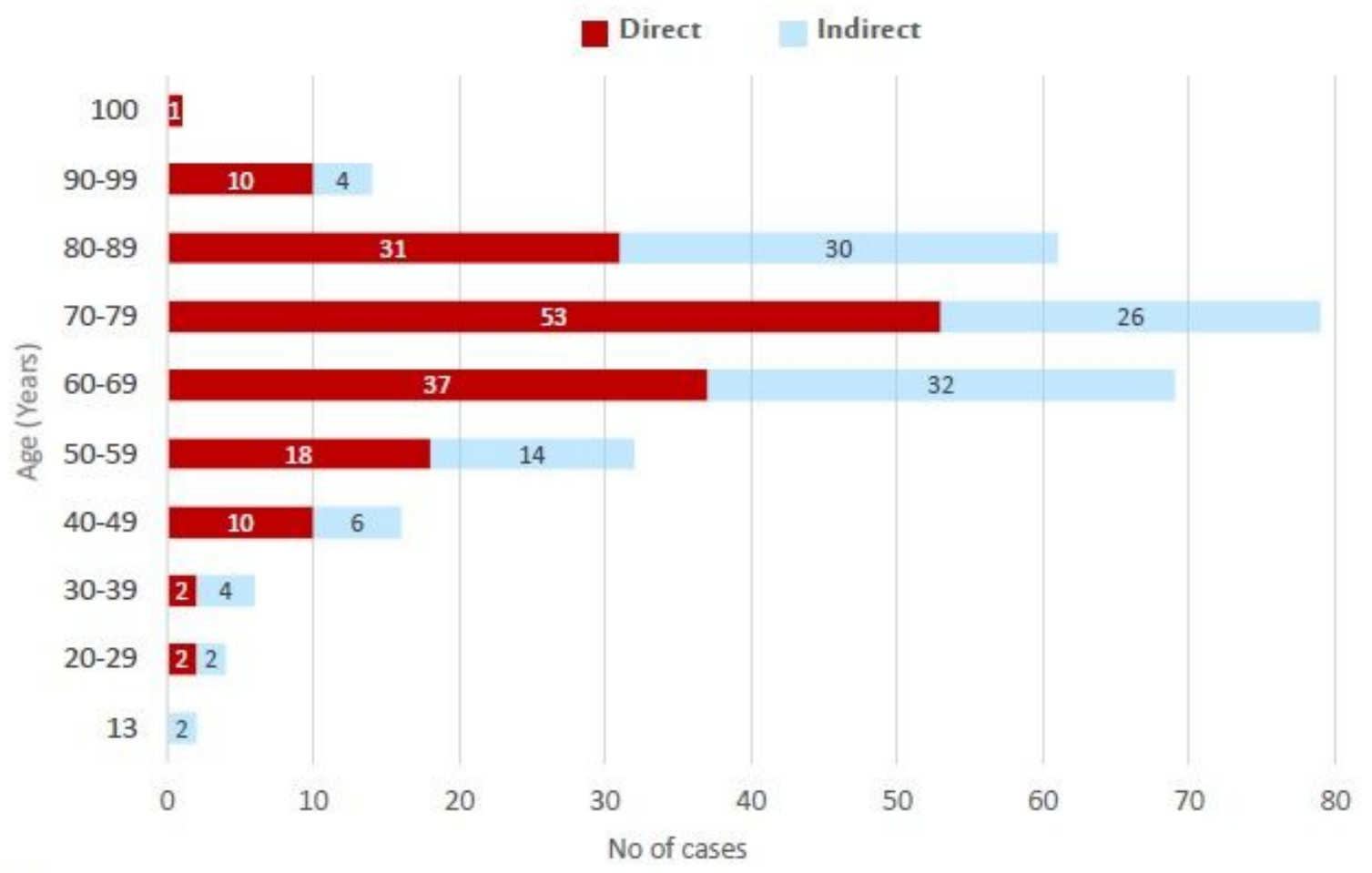

(B)

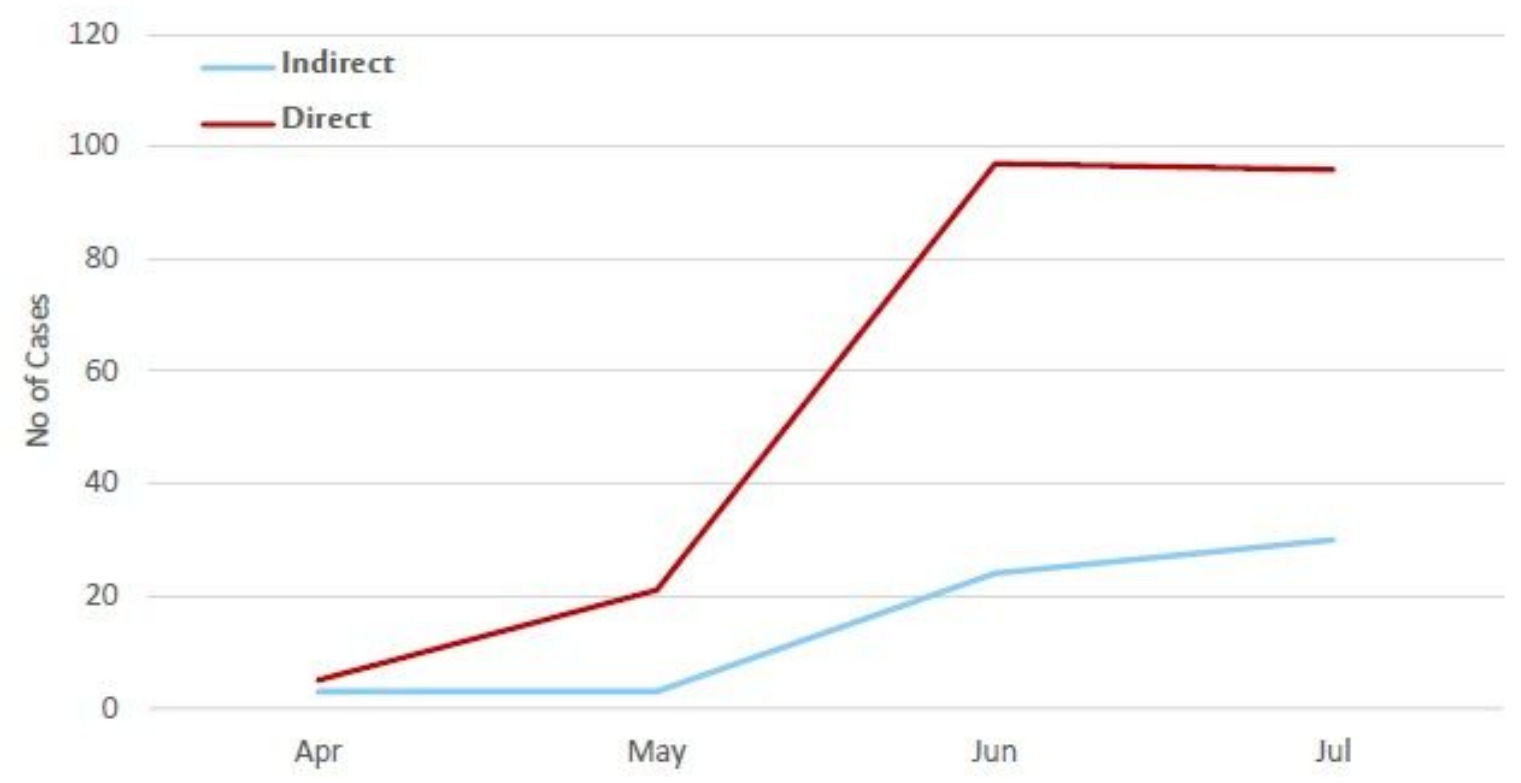

Figure 1

Distribution of Coronavirus disease 2019 (COVID-19) mortality cases (A) Distribution of Coronavirus disease 2019 (COVID-19) mortality cases stratified by age and cause of death from (Direct Indirect), (B) and date of death from COVID-19 stratified by Cause of death (Direct Indirect). $(n=224)$ 


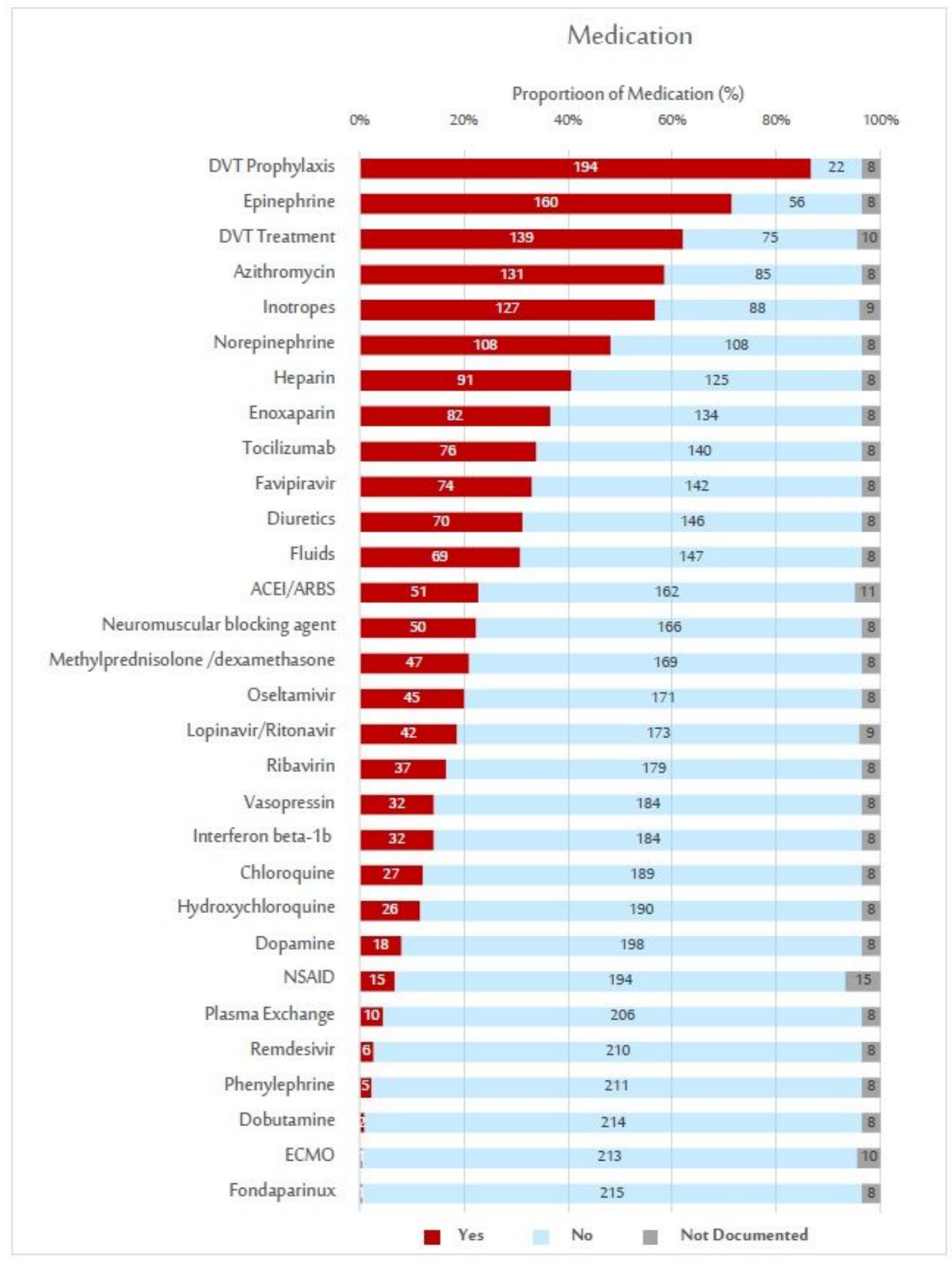

\section{Figure 2}

Medication of Coronavirus disease 2019 (COVID-19) mortality cases admitted to Armed Forces Medical Services Hospitals (MSD), $(n=224)$ 


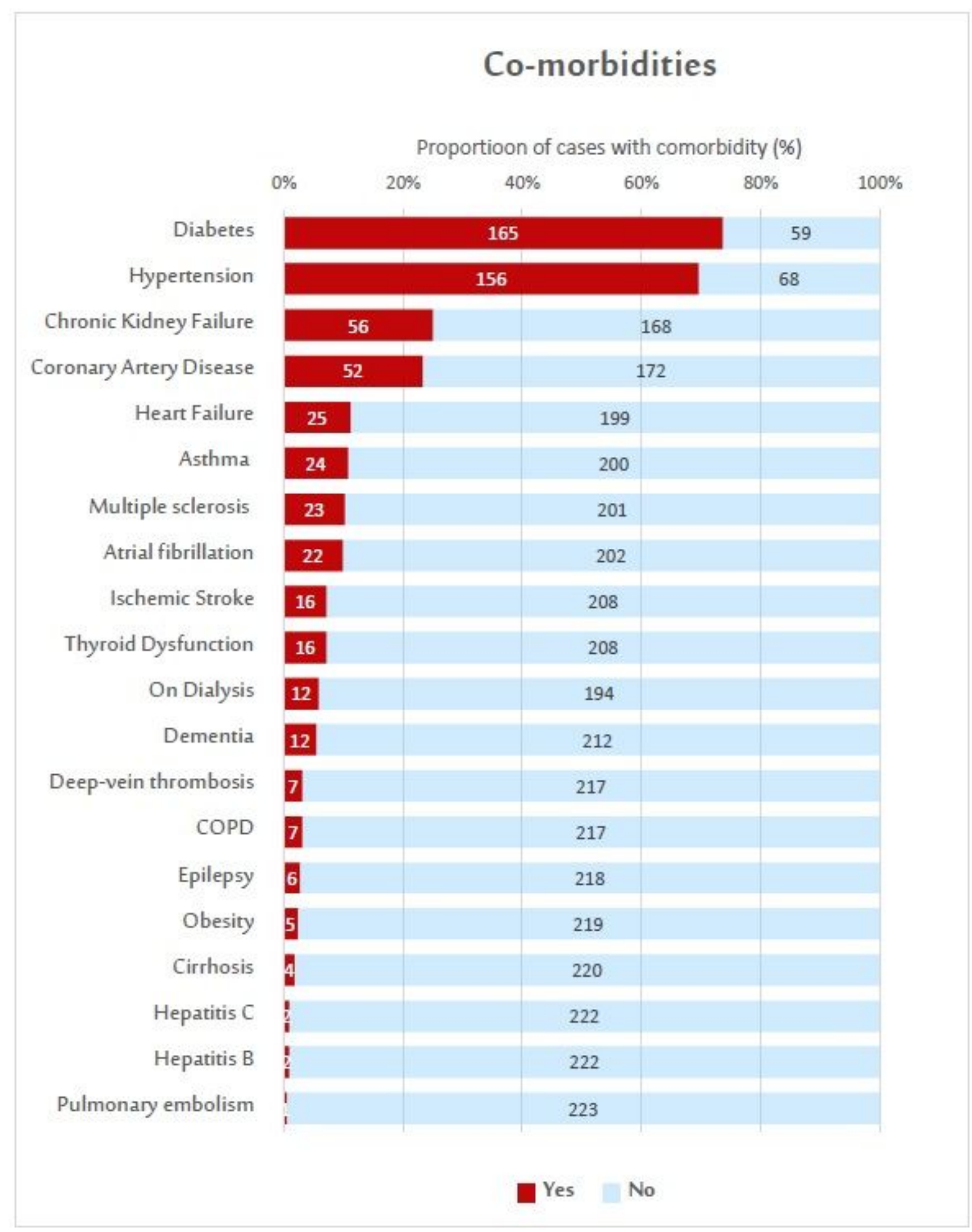

\section{Figure 3}

Co-morbidities of Coronavirus Disease 2019 (COVID-19) Mortality Cases Admitted to Armed Forces Medical Services Hospitals (MSD) ), $(n=224)$ 


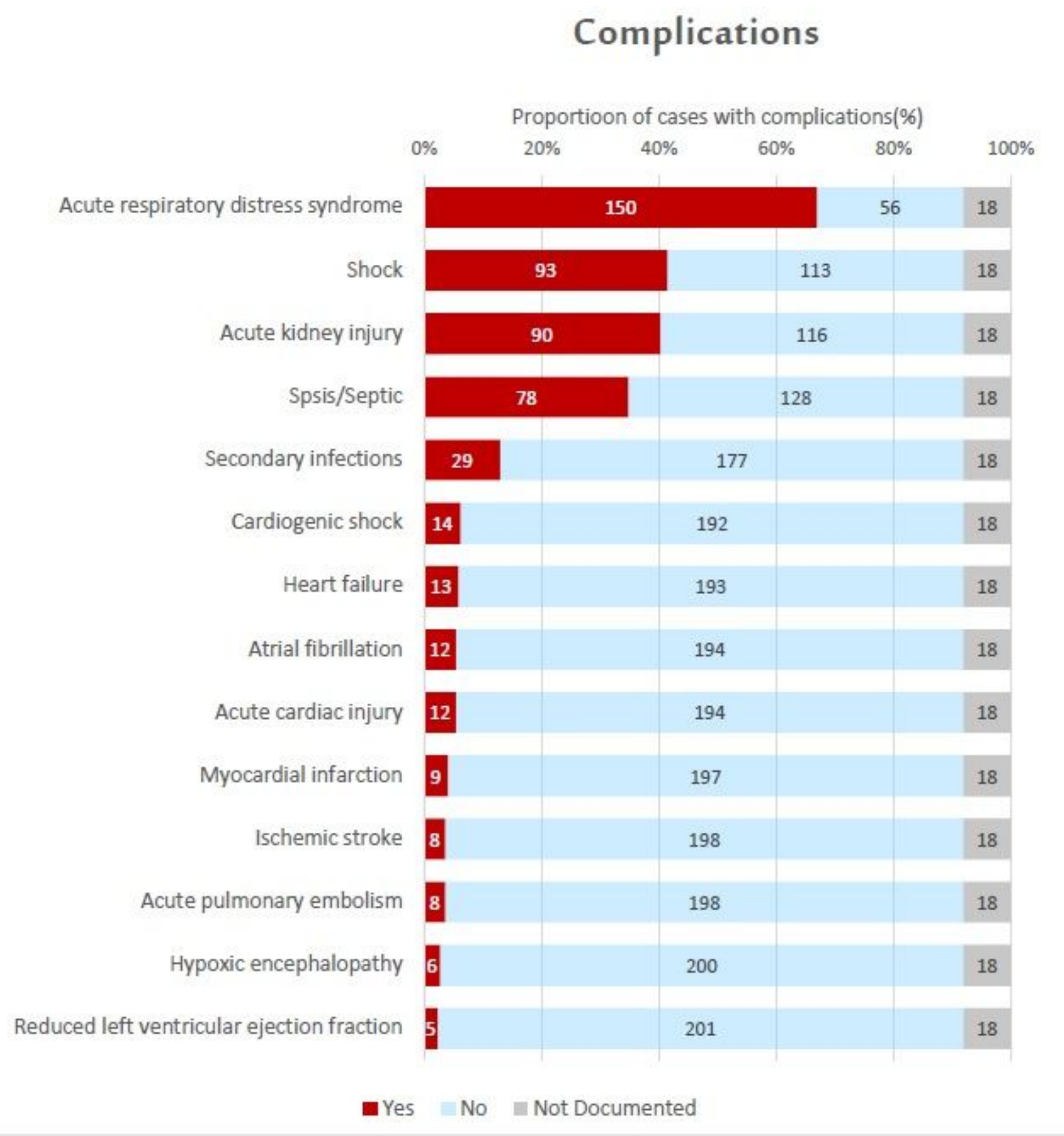

\section{Figure 4}

Complications of Coronavirus Disease 2019 (COVID-19) Mortality Cases admitted to Armed Forces Medical Services Hospitals (MSD) ), $(n=224)$ 

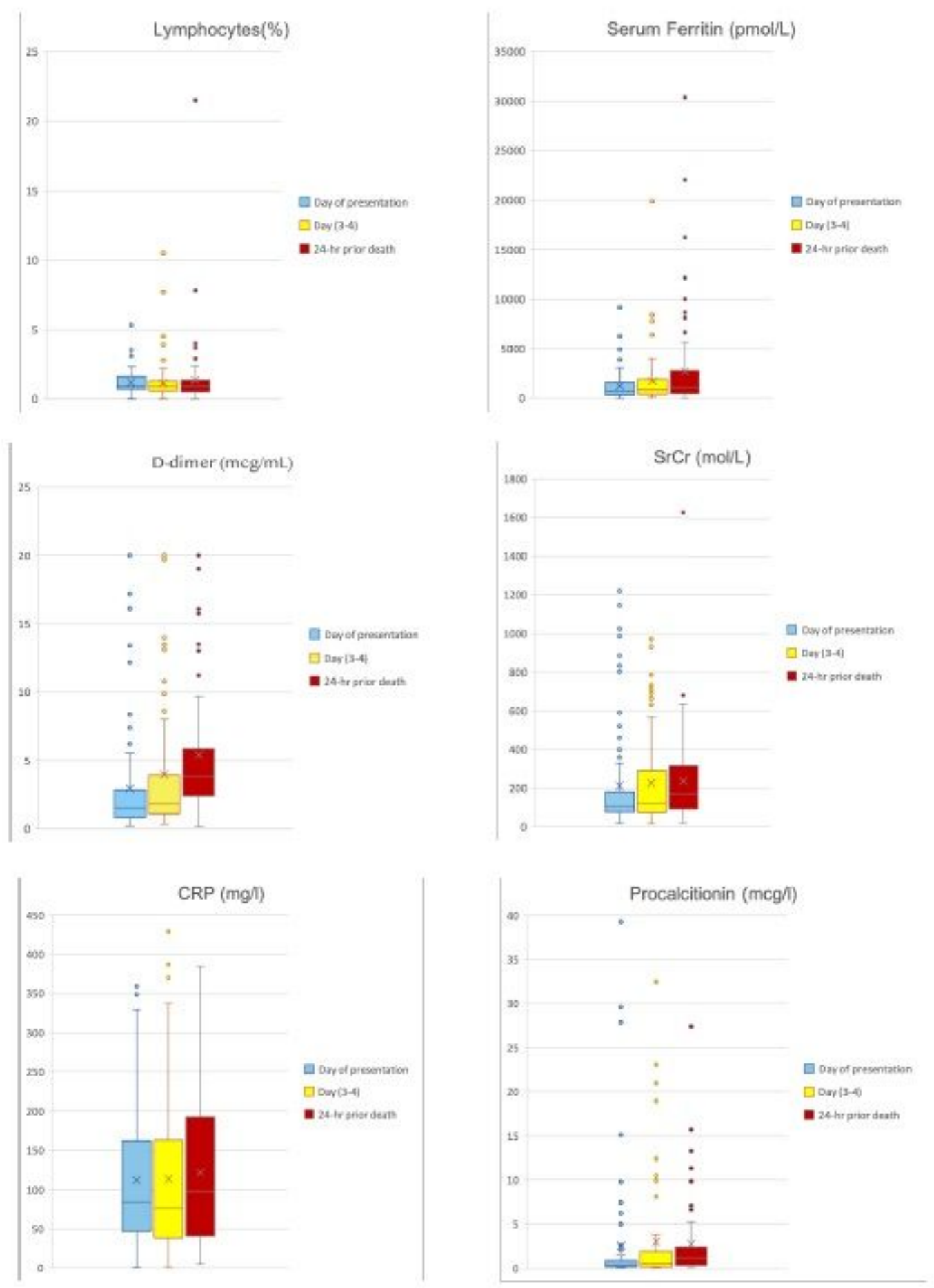

Figure 5

Biomarker Trends of Coronavirus Disease 2019 (COVID-19) Mortality Cases Admitted to Prince Sultan Military Medical City , $(n=115)$ 
(A)

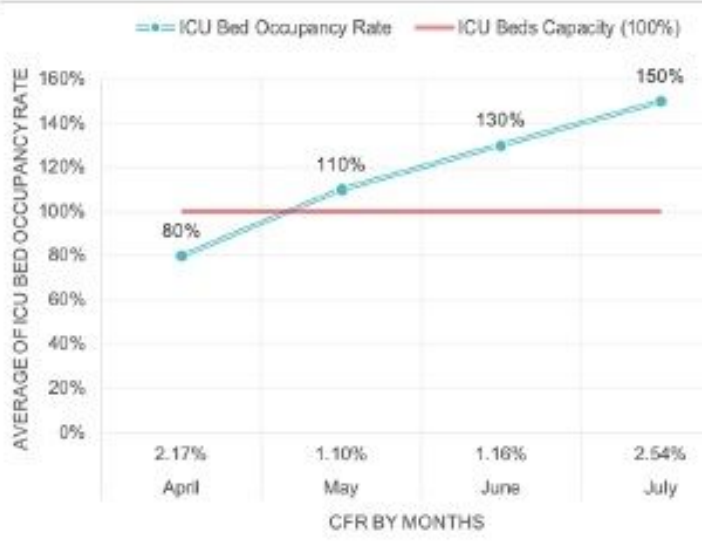

(C)

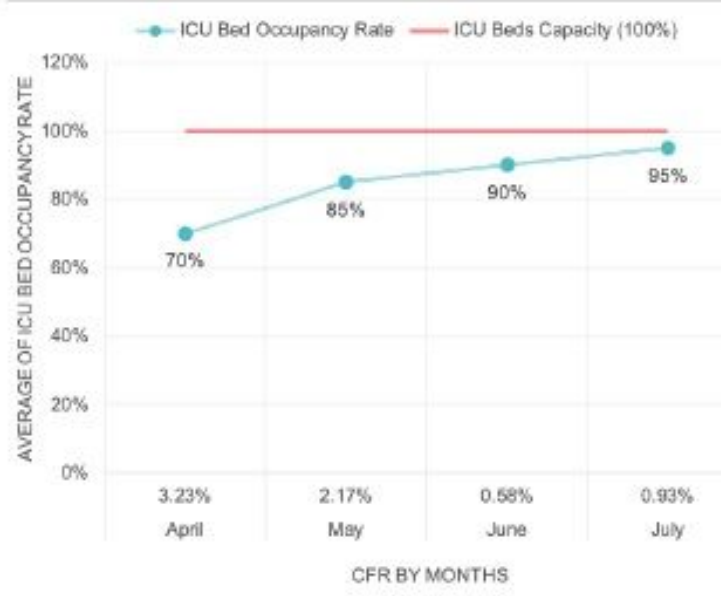

(E)

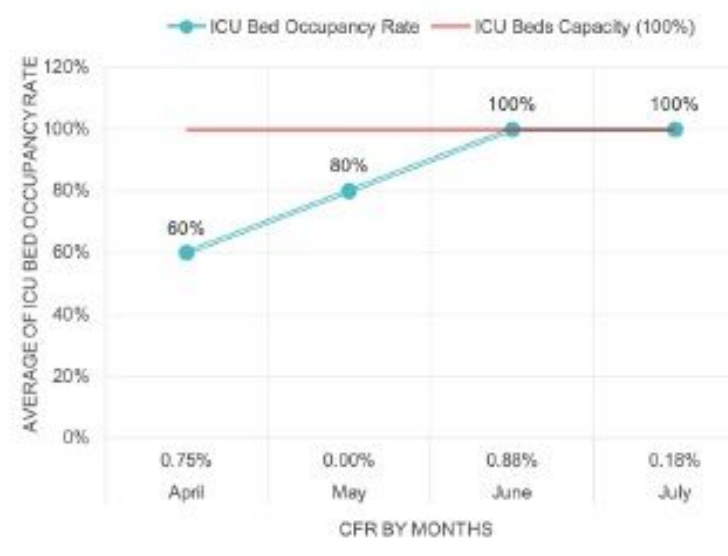

(B)

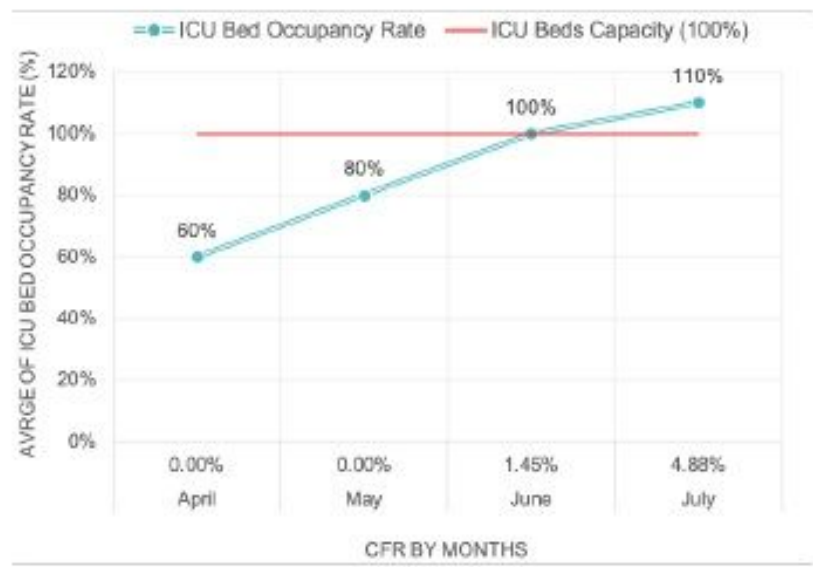

(D)

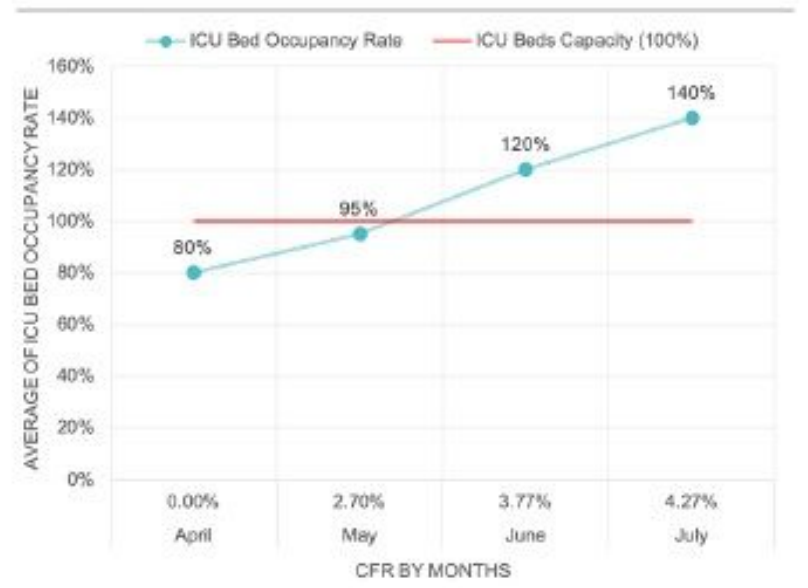

(F)

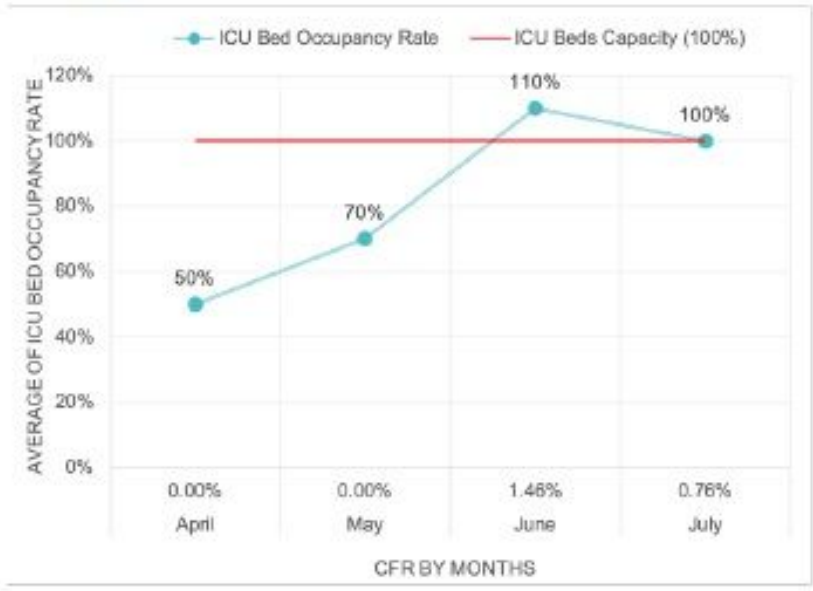

\section{Figure 6}

Case Fatality Rate (CFR) of Coronavirus disease 2019 (COVID-19) Stratified by Month and The Average of ICU Beds Occupancy Rate, for the highest 6 Cities in KSA (April- July 2020). (A)Riyadh, (B) Khamis Mushait, (C)Taif, (D) Al-Kharj, (E)Jeddah, (F) Tabuk. 
(A)

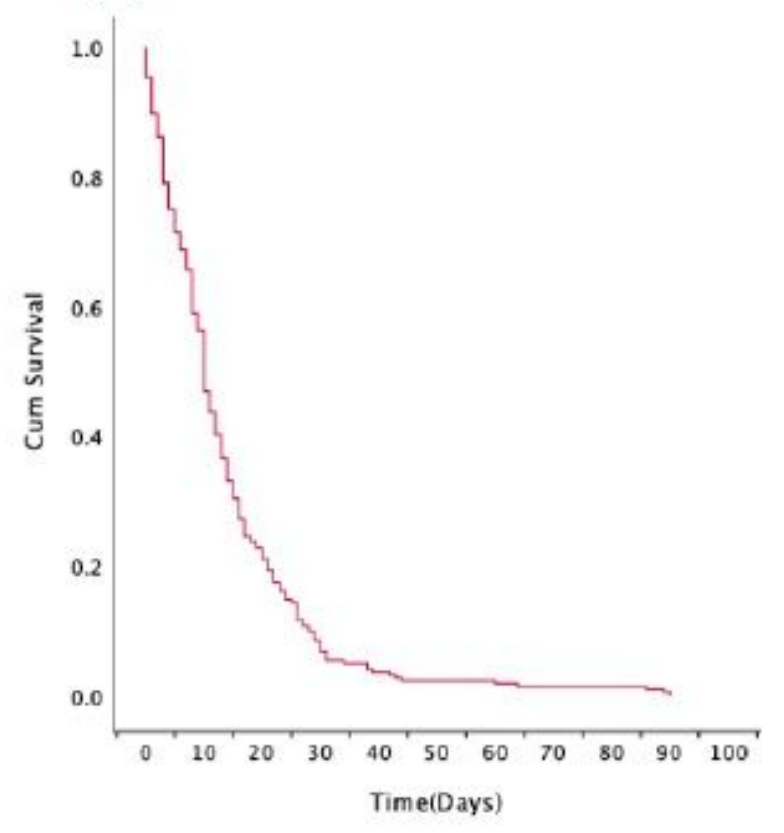

(C)

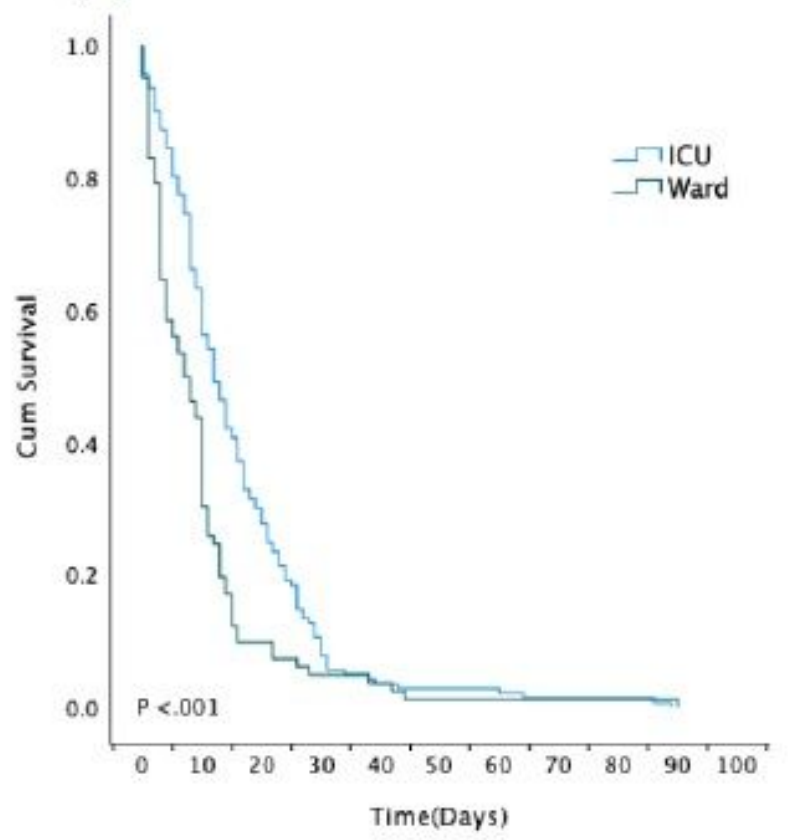

(B)

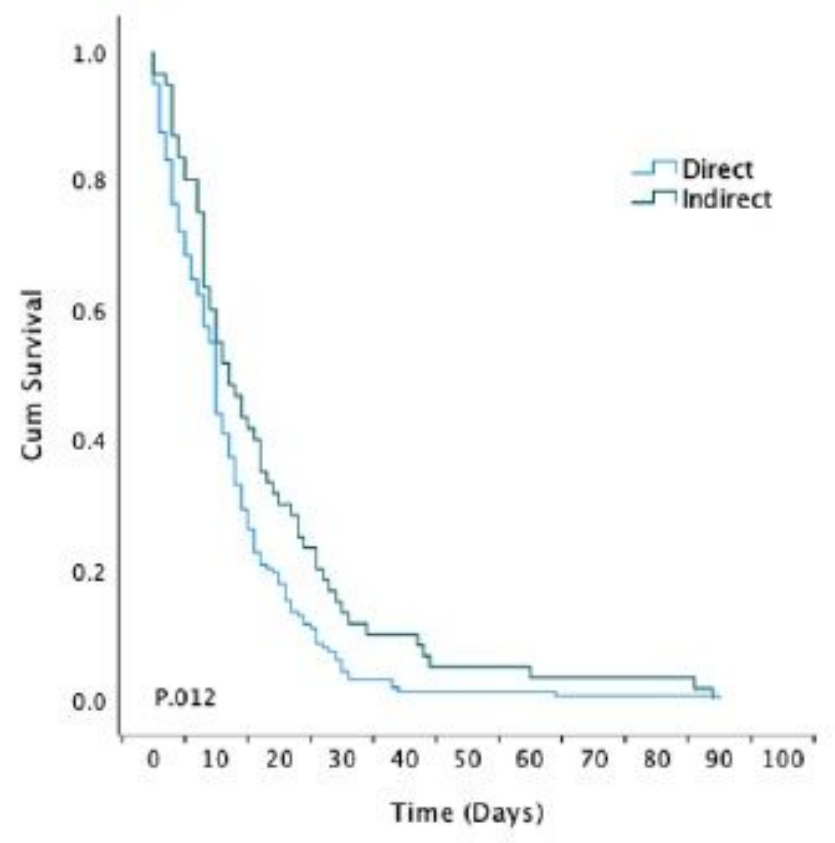

(D)

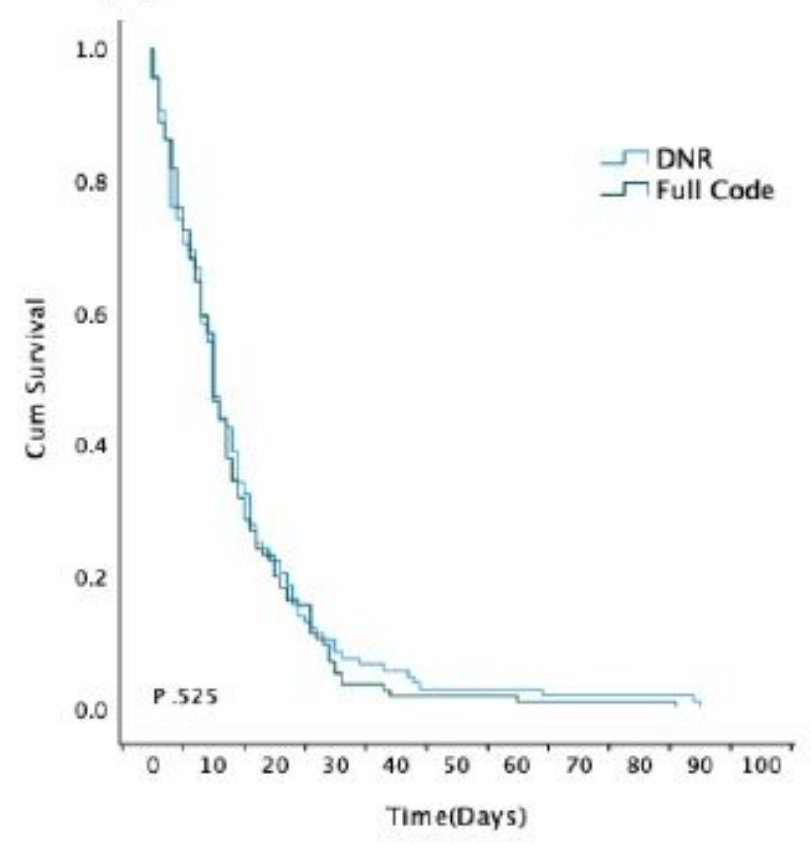

\section{Figure 7}

Kaplan-Meier Analysis of Survival (Time to death) of Coronavirus Disease 2019 (COVID-19) Mortality Cases (A) Analysis of Survival of All COVID-19 Mortality Cases. (B) COVID-19 Mortality Cases Stratified by ( Direct- Indirect) as a cause of death. (C) COVID-19 Mortality Cases Stratified by (Intensive Care Unit/General Ward) admission. (D) COVID-19 Mortality Cases Stratified by (DNR - Full Code). 